\title{
Gattungen und Gattungsanalyse
}

Die Gattungsanalyse (GA) ist von doppelter Bedeutung für die vorliegende Fallstudie: Erstens aufgrund ihres sprach- bzw. kommunikationssoziologischen Kontexts: Vor dem Hintergrund der gesetzten Fragestellung und des empirischen Gegenstand, der explizit eine Kommunikationsform im Sinne des KoKo darstellt (Abschnitt 1.1 und 1.2.2), bietet sich die kommunikativ-konstruktivistisch informierte GA für die Analyse des Group-Talks an. Sowohl der auf einer verstehenden Soziologie basierende Sozialkonstruktivismus (Abschnitt 2.1 und 2.2.2) als Vorläufer der GA und seine ,empirisch aktualisierte" Variante, der kommunikative Konstruktivismus als ihr direkter Nachfolger (insbesondere der hier erweiterte Kommunikationsbegriff; Abschnitt 2.2), als auch die sprachtheoretischen Entwicklungen, die dem von Luckmann konzipierten Gattungsbegriff vorangegangen sind (Abschnitt 3.1), und schließlich auch die Methodologie, die sich an die GA anschließt, Fokussierte Ethnographie und Videographie (Abschnitt 1.2.3), sind von zentraler Bedeutung für meine Forschungsperspektive.

Zweitens stellt die GA eine Forschungsholistik dar, die es mir erlaubt, die heterogenen Datensorten, die im Feld erhoben wurden, sowie die unterschiedlichen sozialen Aggregatsstufen, Mikro-, (Meso-) und Makrostrukturen, die mit diesen Datensorten korrespondieren, in der Analyse systematisch miteinander zu verknüpfen (siehe Abbildung 1.6). Somit ermöglicht die GA es zu vermeiden, was Lettkemann $(2016,51)$ unter dem Begriff der „,soziologischen Unschärferelation“ versteht. Gemeint ist, die Schwierigkeit, Handeln und Institutionen gleichermaBen in den Fokus einer soziologischen Analyse einzubeziehen, ohne dabei das eine oder andere aus den Augen zu verlieren.

Mit der Unschärfe-Metapher erklärt Lettkemann daher, dass Fallstudien in der Regel nur eine der beiden Strukturebenen wählten. Die GA dagegen ist als Forschungsmethode sowie vor ihr bereits Luckmanns Sprachsoziologie und Die gesellschaftliche Konstruktion der Wirklichkeit (Berger und Luckmann 
1986/1969[engl. 1966]) im Theoriebereich, ausdrücklich dazu angetreten, um die Lücke zwischen den Ebenen des kommunikativen Handelns und der institutionellen Struktur des Sozialen zu schließen. Dies entspricht Luckmanns allgemeinem Anspruch, „Handlungstheorie und Institutionenlehre“ $(1992,1)$ in der soziologischen Analyse miteinander zu verbinden. In Vorbereitung auf die Luckmannsche Sprachsoziologie bzw. die spätere GA waren, wie eingangs erwähnt, maßgeblich auf dem Gebiet der Linguistik, methodologische wie theoretische Entwicklungen entscheidend, die ich im Folgenden skizzieren möchte, bevor ich konkret auf das Programm der sprach- (Abschnitt 3.2) bzw. kommunikationssoziologischen GA (Abschnitt 3.2.3) eingehen werde.

\subsection{Bausteine der wissenssoziologischen GA}

Die maßgebenden Vorläufer der sprach- bzw. wissenssoziologischen GA (Abschnitt 3.2) finden sich in den USA. Hier sind es neben Pionierarbeiten, die bis in die Zeit der Chicago-School der 1920er Jahre zurückreichen (Knoblauch 2000, 47), vor allem die Anfang der 1960er aufkommende Ethnographie des Sprechens (Hymes 1962) bzw. die Soziolinguistik ${ }^{1}$ - nebst den Arbeiten von Erving Goffman, die ihr zugerechnet werden können (Bergmann 1991) - und die etwas jüngere ethnomethodologisch informierte CA (Sacks et al. 1974), die als Ideengeber für die GA von Luckmann betrachtet werden müssen.

\subsubsection{Die Entwicklung der Soziolinguistik}

In der Soziolinguistik wird das Phänomen der Sprache empirisch, d. h. in ihrem alltäglichen Gebrauch, erforscht (Ethnographie des Sprechens) und daher als „parole“, also als Handeln (Knoblauch 2000, 48) aufgefasst. Hier unterscheidet die Soziolinguistik sich entschieden vom Paradigma der strukturalistischen

\footnotetext{
${ }^{1}$ Der Begriff Soziolinguistik (Sociolinguistics) wird gelegentlich Haver Currie (1952) zugeschrieben (Knoblauch 2000, S. 48), wohingegen eine Kurznotiz in Language in Society vom April 1979 (Hymes 1974, 141) darauf aufmerksam macht, dass er bereits 1939 von T.C. Hodson (in Language in Society fälschlicherweise Hudson geschrieben) im Titel einer Arbeit über Sanskrit gebraucht wurde (Hodson 1939). Den Begriff der Ethnographie des Sprechens schreibt Hymes sich selbst (als „Motto“) zu (Hymes 1979, $96 f$.). Größere Popularität erfuhr allerdings dessen Weiterentwicklung zur Ethnographie der Kommunikation (Hymes 1964), der deshalb im Folgenden verwendet wird, ,ein Begriff, der allerdings den dynamischen und praxisorientierten Aspekt der sprachlichen Performanz weniger stark betont als sein Vorgänger“ (Bergmann und Meyer 2011, 151).
} 
Linguistik, die von Ferdinand de Saussure begründet, Sprache als Zeichensystem auffasst und somit weitgehend auf ihre Darstellungsfunktion reduziert. ${ }^{2}$ Die systematische Unterscheidung zwischen gesprochener Sprache und Sprache als Zeichensystem stammt von de Saussure selbst: Er differenzierte zwischen „langue“ (Zeichensystem), „parole“ (gesprochene Sprache) und „langage“ (das Gesamtsystem). Die Linguistik definierte er vor dem Hintergrund dieser Differenz ausdrücklich als Wissenschaft, ,deren einziges Objekt die Sprache als System [langue] ist" (Saussure 2016, 25, Volosinov 1973, 59). Für Luckmann, dem es um das (kommunikative) Handeln geht, ist de Saussure vor diesem Hintergrund nicht anschlussfähig. Die Soziolinguistik hingegen, mit ihrer Praxis-Wende in der Sprachforschung, vermag entscheidende Impulse für seine Sprachsoziologie (Luckmann 1975, 9) und die spätere GA zu liefern. Und auch für Forscher/-innen der ethnomethodologischen Schule, in deren Umfeld schließlich die CA von Harvey Sacks (Abschnitt 3.1.4) entwickelt wird sowie für Goffman (Abschnitt 3.1.5) ist die Soziolinguistik ein Anziehungspunkt.

Im Jahr 1972, als Vorsitzender des Round Table on Linguistics and Language Studies der Universität von Georgetown, hielt der Anthropologe und Sprachwissenschaftler Dell Hymes, der neben dem Linguisten John Gumperz als Hauptvertreter der Soziolinguistik gilt, eine Rede, in der er das entsprechende Programm einerseits gegenüber dem damals dominanten Saussurschen Paradigma der Linguistik, andererseits aber auch gegenüber den Anfängen der Soziolinguistik selbst, mit einiger Schärfe ausführte. Die Entwicklung des soziolinguistischen Forschungsprogramms war zum damaligen Zeitpunkt bereits seit etwa einem Jahrzehnt vorangeschritten. Es hatte dabei aber nicht die durchschlagende Wirkung in der institutionellen Linguistik erzielen können, die Hymes sich erhofft hatte: ${ }^{3}$ „I take it that most of us aim higher than that" ( (Hymes 1972,

\footnotetext{
${ }^{2}$ Nach dem Kommunikationsmodell von Karl Bühler (Bühler 1934) besitzt die Sprache drei Funktionsbereiche: Die Ausdrucks-, die Appell- und die Darstellungsfunktion. Während Erstere der Äußerung von Innerem dient und Mittlere die Funktion der Adressierung umfasst, beschreibt Letztere die eigentliche Zeichentheorie, d. h. die Tatsache, dass Worte Dinge bezeichnen, mit denen sie nicht identisch sind.

${ }^{3}$ Noch im Jahr 1972 war die Soziolinguistik so ,neu', dass sich die Veranstalter/-innen des Twenty-Third Annual Georgetown University Round Table on Linguistics and Language Studies, unter dem Vorsitz von Dell Hymes, nicht sicher waren, ob ihr Call zu dem Thema Sociolinguistics: Current Trends and Prospects ausreichende Aufmerksamkeit auf sich ziehen würde: „It was with some hesitation that this topic was originally suggested since the development of sociolinguistics is so recent that the committee was not at all certain how widely it would be received. However, the response to the initial announcement was overwhelming“ (Shuy 1972, V). U.a. sprachen William Labov, Aaron Cicourel, Dell Hymes, Joshua Fishman, Harvey Sacks, John Gumperz und - last but not least - Erving Goffman,
} 
314); dazu (Coulmas 1979, 7)). Während, wie er schilderte, bereits eine große Zahl empirischer Arbeiten auf dem Ansatz der Ethnographie der Kommunikation beruhten (oder sich auf ihn beriefen), sei die Linguistik als Theorie noch weit davon entfernt, die soziale Perspektive als elementaren Bestandteil integriert zu haben. Vielmehr sei sie eine ,theory of grammar" (Hymes 1972, 316) geblieben. Die Perspektive der Soziolinguistik sei daher stets lediglich ein Teilaspekt angewandter Linguistik, anstatt die Grundlage für eine neue linguistische Theorie darzustellen (ebd.).

Hymes Ärger über diese Diagnose ist zu verstehen, schloss die Soziolinguistik doch an eine Forderung an, die u. a. bereits von dem berühmten und einflussreichen amerikanischen Linguisten Edward Sapir in den 1920er Jahren aufgestellt wurde. Dieser appellierte 1928, also bereits vier Jahrzehnte vor Hymes' Rede am Round Table, bzw. drei Jahrzehnte vor den ersten Arbeiten im Bereich der Ethnographie der Kommunikation, die Linguistik müsse sich mit , anthropologischen, soziologischen und psychologischen' Problemen beschäftigen, insofern sie Sprache beträfen:

It is peculiarly important that linguists, who are often accused, and accused justly, of failure to look beyond the pretty patterns of their subject matter, should become aware of what their science may mean for the interpretation of human conduct in general. Whether they like it or not, they must become increasingly concerned with the many anthropological, sociological, and psychological problems which invade the field of language. (Sapir 1929, 214)

Mit seinem Anliegen folgte Hymes also einem Imperativ, der schon lange vor ihm im Feld formuliert worden war. Nun erwartete er eine, realistische', d. h. am tatsächlichen Sprachgebrauch orientierte ,sozial-konstituierte' Linguistik:

The phrase 'socially constituted' is intended to express the view that social function gives form to the ways in which linguistic features are encountered in actual life. This being so, an adequate approach must begin by identifying social functions, and discover the ways in which linguistic features are selected and grouped together to serve them. (Hymes 1972, 316)

Der Anthropologe und Linguist Hymes ist der Ansicht, Sprachforschung müsse sich, basierend auf anthropologischer Methodologie und soziologischer Erkenntnisse, auf soziale Konstituenten rückbeziehen, um so, im Sinne einer SozioLinguistik, Kommunikationsformen identifizieren und analysieren zu können,

dessen Manuskript auf eigenen Wunsch allerdings nicht in der Tagungspublikation erschien (ebd.). 
in denen Sprache im Alltag tatsächlich gebraucht wird. Es geht ihm darum, im Rahmen eines entschieden empiristischen Ansatzes, Sprech- bzw. Kommunikationsereignisse (speech events (Hymes 1979, 47 ff) bzw. communication events (Hymes 1964, 13)) als Hauptgegenstand einer neuen (Ethno-)Linguistik zu etablieren, um so, auf der Basis ,fokussierter Ethnographien", den Begriff der Sprache in Hinblick auf deren Funktionen in tatsächlichen Sprachgebräuchen bestimmen zu können. Es gelte herauszufinden, so Hymes, wie Sprecher/-innen konkreter Sprechgemeinschaften (speech communities) bestimmte Eigenschaften von Sprache auswählten und ,gruppierten“, um so spezifische soziale Zwecke ihrer Kommunikation zu realisieren.

Neben den Begriffen Sprechereignis und Sprechgemeinschaft umreißt Hymes den Analyserahmen seiner Ethnographie des Sprechens mit weiteren Begriffen, die in der Literatur als analytische Beschreibungssprache, nicht zuletzt in Luckmanns Sprachsoziologie, (zumeist unsystematisch) Verbreitung fanden und die Hymes z. T. der einschlägigen Literatur entnahm; darunter Sprechsituation (speech situation; (Austin 1962)), Sprechakt (speech act; (Austin 1962); (Searle 1969)) und $\ddot{\text { u} ß e r u n g s k o n t e x t ~(s e t t i n g ; ~ i n ~ A n l e h n u n g ~ a n ~ J a k o b s o n s ~ K o n-~}$ text (1960)). In einem Artikel stellt Hymes (1964) zudem ein detailliertes Glossar zusammen, wie die einzelnen relevanten Elemente (community, situation, event, act, setting) der Ethnographie der Kommunikation zu operationalisieren seien bzw. worauf es konkret zu achten gelte, wenn man Feldforschung durchführe. Ausdrücklich bezieht er sich dabei auf die Arbeit des Linguisten Roman Jakobson, dessen sechs Faktoren der Mitteilung er aufnimmt und ergänzt. ${ }^{4}$

Briefly put, $(1,2)$ the various kinds of participants in communicative events-senders and receivers, addressors and addressees, interpreters and spokesmen, and the like; (3) the various available channels, and their modes of use, speaking, writing, printing, drumming, blowing, whistling, signing, face and body motion as visually perceived, smelling, tasting, and tactile sensation; (4) the various codes shared by various participants, linguistic, paralinguistic, kinesic, musical, and other; (5) the settings (including other communication) in which communication is permitted, enjoined, encouraged, abridged; (6) the forms of messages, and their genres, ranging verbally from singlemorpheme sentences to the patterns and diacritics of sonnets, sermons, salesmen's pitches, and any other organized routines and styles; (7) the topics and comments that a message may be about; (8) the events themselves, their kinds and characters as

\footnotetext{
${ }^{4}$ Aufbauend auf Bühlers Kommunikationsmodell (vgl. Fußnote 42), entwickelte Jakobson (1960) ein Modell, wonach jedem Kommunikationsereignis sechs Faktoren zugrunde liegen: Sender, Empfänger, Kontakt, Code, Kontext und Botschaft (ebd., S. 358). Hymes greift diese sechs Faktoren auf und ergänzt sie um die Formen der Mitteilung sowie das Kommunikationsereignis selbst.
} 
wholes-all these must be identified in an adequate ethnographic way. (Hymes 1964, 13)

\subsubsection{Luckmanns Sprachsoziologie}

Vor dem Hintergrund dieser Neuausrichtung der Linguistik, die Hymes beschwört und für die er ein umfangreiches theoretisches wie Empirie-anleitendes Begriffsrepertoire aus der linguistischen Forschung zusammenstellt, lag es nahe, nicht zuletzt aus sozialkonstruktivistischer bzw. wissenssoziologischer Perspektive, die Luckmann mit Berger entwickelt hatte, an Hymes und John Gumperz anzuschlieBen und nach den Gruppierungen oder besser: den Institutionen der Sprache zu suchen, die gesellschaftliche Wirklichkeit praktisch im Alltag zu konstruieren erlauben. In Anschluss an die Soziolinguistik entwirft Luckmann daher eine Sprachsoziologie (1975), in der er die Forderungen von Sapir bzw. Hymes von der (Sozio-)Linguistik auf die Soziologie spiegelt. Er beklagt, "it comes as a surprise to discover how superficial sociology's interest in language has been until the recent past" (ebd., S. 8). Luckmann hingegen interessierte sich seit den frühen 1970er Jahren konkret für die Soziologie der Sprache. Zuvor hatte er vergleichende Sprachwissenschaft studiert, wobei es ihn überraschte, wie wenig diese mit tatsächlich gesprochener Sprache zusammenhängen konnte (Luckmann 2013, 41 f.):

[T] he dominant approach was either philological in the old sense or what appeared as abstract structuralism to an impatient student who was looking in vain for la parole in the study of la langue. (ebd.)

Angesichts dieser Studienerfahrung in der Linguistik nimmt Luckmann in The Sociology of Language (1975), inspiriert von so heterogenen Klassikern wie von Humboldt (Philologie), Émil Durkheim (Soziologie) und Mead (Sozialpsychologie), die Arbeiten Hymes' und Gumperz aus der (anthropologischen Sozio-) Linguistik auf. Ohne die GA dabei bereits vorzuschlagen oder als Methode zu entwerfen, den Begriff der Gattung verwendet er nicht, entwickelt Luckmann hier, entlang der in der Wissenssoziologie ausgearbeiteten Grundbegriffe wie Institution und Sozialisation, die Grundlagen der GA. Er erläutert, unter dem Begriff der institutionellen Sprache (institutional language), dass spezifischen sprachlichen Repertoires bzw. Sprechweisen, spezifische Rollen, Status und Biografien zugeordnet werden können.

Im Kontext der sozialen Situation, die er maßgeblich durch die institutionalisierte Sozialstruktur definiert sieht (ebd., S. 44), verdeutlicht Luckmann 
zudem, dass auf Grundlage der wechselseitigen Definition der Kommunizierenden (informelle Situation) oder von institutionellen Vorgaben (formale Situation) der spezifische Sprachgebrauch in Situationen, ,with varying degrees of precision and articulation“ (ebd.), vorfestgelegt und es umgekehrt deshalb so sei, dass spezifischer Sprachgebrauch es den Kommunizierenden erlaube, Rückschlüsse auf die wechselseitige Einschätzung, ihre Beziehung zu einander sowie die Natur der gemeinsamen sozialen Situation zu ziehen:

[I]t should be noted that institutionally defined roles, political roles, professional roles, etc., have characteristic linguistic repertoires. Social positions, e.g., class and other status, are marked by distinct styles of language or other variations of linguistic codes. A person is institutionally and "positionally" (i.e., by status) socialized in the course of his social biography to one or several linguistic repertoires and to one or several speech styles simultaneously or consecutively. The use of a particular linguistic repertory or a particular speech style (e.g., formal instead of intimate) in particular social situations is generally motivated by the social biography of the person. In addition, the specific use in specific situations is determined by the reciprocal definitions of the situation of the participants, or may be imposed by institutional sanctions. Conversely, in social situations the linguistic typifications by the participants of each other and of themselves in relation to the others as well as of the situation itself, are of particular importance for the possibility and realization of congruent intersubjective definitions of the situation. (ebd., S. 21)

In sozialen Situationen sieht Luckmann das Sprechen, in Einklang mit seiner im SoKo detailliert ausbuchstabierten Institutionalisierungsthese (Abschnitt 2.2.2), als maßgeblich durch soziale Institutionalisierung bzw. die institutionelle Sprache determiniert. Mit einer starken Betonung auf die strukturelle Kraft sozialer Institutionen meint Luckmann, Rollen und Statusaspekte wirkten geradezu ,automatically“ (ebd., S. 44), wobei sie spezifische Sprachstile und -repertoires aktivierten. Die ,stylistic “degrees of freedom”“" variieren dabei zwar von ,society to society and from situation to situation" (ebd.). Mit Verweis auf empirische Studien zeigt Luckmann aber, dass konkrete Sprechakte dabei situativ stets in engem Zusammenhang mit relevanten Aspekten der sozialen Wirklichkeit, die die soziale Situation rahmen, ausgewählt werden: Verwandtschaft, Alter und Geschlecht, ökonomische oder politische Institutionen, Statusunterschiede und allgemeine gesellschaftliche Normen, wie das Ernste, das Feierliche, das Heilige usw. sind demnach sozialstrukturelle Faktoren, die die Auswahl sprachlicher Elemente und sprachlicher Formen maßgeblich beeinflussen: 
C.O. Frake (1964) demonstrated convincingly that a complex interplay of sociostructural, cultural and linguistic factors of the kinds described above is presupposed in such a seemingly simple speech-act as the ordering of a drink. (ebd., S. 45)

Bei aller Betonung der sozialen Strukturen und ihrer z. T. determinierenden Wirkung auf unser (kommunikatives) Handeln, nämlich die Auswahl unserer Sprechakte, vergisst Luckmann in seinen Ausführungen nicht, im Sinne des , verstehenden“ Anspruchs und der dialektischen Betrachtungsweise von Mensch und Gesellschaft im SoKo, darauf hinzuweisen, was sich bereits in den angesprochenen Freiheitsgraden des institutionellen Sprechens andeutet: Dass soziale Situationen natürlich nicht vollständig institutionalisiert sind, sondern durch die Anwesenheit von Subjekten stets auch eine aktuelle und individuelle, subjektive Seite aufweisen, ein Hier-und-Jetzt, das von der sozial-biographischen Determiniertheit des Sprechens unterschieden werden muss, dabei aber nicht weniger determinierend wirkt als die Institutionen des Sozialen (siehe Abschnitt 2.1.1 bis 2.1.3):

There is, however, an entire set of intrinsic determinants that must be considered separately. They originate in the "inner" structure of the situation and influence the form of the speech-act from "within". As far as the individual is concerned, each situation is subjectively structured in various ways: spatially (into left and right, up and down, near and far), temporally (into before and after, soon and late, etc.), socially (according to the immediacy of the several symptoms-optical, acoustic, tactile, etc.) and to the permutations of these symptoms by which partners in the situation are experienced. (ebd.)

In seiner Sprachsoziologie von 1975 greift Luckmann den Begriff der Gattung, auf dessen Spuren ich mich in diesem Abschnitt meiner Arbeit noch etwas weiterbewegen möchte, noch nicht auf. Er verwendet stattdessen den sozialkonstruktivistischen Begriff der institutionellen Sprache. Dabei argumentiert Luckmann vor allem, dass Sprechen weitgehend von institutionellen Kontexten determiniert sei. Er stellt dar, dass Sprechen in sozialen Situationen an Faktoren der sozialen Biografie sowie allgemeine gesellschaftliche Normen gebunden sei. Wobei er zugleich auf den wichtigen Aspekt hinweist, dass nicht nur äußere institutionelle, sondern, aus der situationalen Perspektive der Sprechenden, auch innere Faktoren Einfluss auf die Wahl von Sprechakten haben. ${ }^{5}$ Die Frage aber,

\footnotetext{
5 Tatsächlich weist ja die Biografie selbst, während sie weitgehend von sozialen Strukturen prädisponiert ist, individuelle bzw. ganz subjektive Eigenschaften auf, wie die spezifische Abfolge, die spezifische räumliche und zeitliche Perspektive etc., worauf Schütz und Luckmann (1979, S. 86) dezidiert hinweisen.
} 
in welchen konkreten Einheiten, Mustern, Formen und Gattungen institutionalisiert gesprochen wird, bleibt in Luckmanns Sprachsoziologie unadressiert. Auch Hymes, der Luckmanns Sprachsoziologie entscheidend bereichert, verwendet den Begriff der Gattung (genre) zu Anfang (Hymes 1964) selten und selbst in seinen späteren Arbeiten nur unsystematisch und weitgehend unerläutert (Günthner und Knoblauch 1994, 698). Das Verhältnis, in dem „,sprachliche Routine“, „Muster“ und „Sprechgewohnheiten“ (Hymes 1979, S. 78 f.) zu Genres bzw. Gattungen stehen, liegt nicht in Hymes Fokus und verbleibt auch bei Luckmann - vorerst - im Dunkeln.

\title{
3.1.3 Der Begriff: Speech Genres
}

Als eigentliche Quelle des Gattungsbegriffs in Bezug auf verbale Kommunikation muss der 1975 verstorbene russische Literaturwissenschaftler Michail Bachtin (engl. Bakhtin) betrachtet werden. Bachtin, den Luckmann 1975 noch nicht rezipierte (Luckmann 2006, 5), schrieb in den 1950er Jahren ein Essay, in dem er den Begriff der Sprechgattung definierte:

\begin{abstract}
All the diverse areas of human activity involve the use of language. Quite understandably, the nature and forms of this use are just as diverse as are the areas of human activity. [...] Language is realized in the form of individual concrete utterances (oral and written) by participants in the various areas of human activity. These utterances reflect the specific conditions and goals of each such area not only through their content (thematic) and linguistic style, that is, the selection of the lexical, phraseological, and grammatical resources of the language, but above all through their compositional structure. All three of these aspects -thematic content, style, and compositional structure- are inseparably linked to the whole of the utterance and are equally determined by the specific nature of the particular sphere of communication. Each separate utterance is individual, of course, but each sphere in which language is used develops its own relatively stable types of these utterances. These we may call speech genres. (Bakhtin 1986[1952], 60)
\end{abstract}

Bachtin, dessen analytische Grundeinheit die Äußerung (utterance) (ebd., S. $67 \mathrm{ff}$ ) im Sinne von Saussures parole ist, entwickelt in seinem Essay, maßgeblich anhand des Dialogs als deren Prototyp, die Theorie einer Linguistik der Sprechkommunikation (speech communication). Seinen Hauptbegriff, die Äußerung, definiert er dabei entlang einer semantischen Dimension: Eine Äußerung kann demnach sowohl ein einzelnes Wort, einen Satz oder eine Vielzahl von Sätzen umfassen (ebd., S. 77). Entscheidend ist die abgeschlossene Sinneinheit der Äußerung (ebd., S. 76), die Vollständigkeit der Ent-Äußerung im Sinne eines 
Sprechplans (speech plan). Mit dem Sprechplan verweist Bachtin darauf, dass wir nicht von Wort zu Wort oder Satz zu Satz kommunizieren. Vielmehr würden wir das Ganze, unseren Ausdruckswillen, im Verlauf des Sprechens mit Worten füllen (ebd., S. 86). Nur so kann der Begriff der Äußerung, im Sinn der Externalisierung eines subjektiven Sinns, überhaupt Bedeutung erlangen. Entsprechend verwirft (auch) er die Analyseeinheiten der etablierten Linguistik nach Saussure: Silben, Worte oder Sätze seien - im Sinne ihrer Darstellungsfunktion - ungeeignet, um der Natur des Sprechens - im Sinne ihrer Ausdrucksfunktion - auf die Spur zu gelangen. Sie seien neutral, besäßen keine Aussagekraft und ,gehörten niemandem': „The words of a language belong to nobody“, „The same thing must be said about the sentence as a unit of language: it, too, is devoid of expressiveness“ (ebd., S. 88 f.). Der wirkliche Charakter der Sprache sei vielmehr nur erfahrbar, wenn man ihn aus der Sprechkommunikation (parole statt langue) heraus analysiere. Hier erweise sich, dass die Grundeinheit die Äußerung sein müsse, da nur in ihr das Wort mit der Wirklichkeit in Kontakt käme, es erst hier einem Ausdruck diene und so für die Sprecher/-in sowie für die Zuhörenden kontextuell sinnhaft interpretierbar sei:

Therefore, one can say that any word exists for the speaker in three aspects: as a neutral word of a language, belonging to nobody; as an other's word, which belongs to another person and is filled with echoes of the other's utterance; and, finally, as my word, for, since I am dealing with it in a particular situation, with a particular speech plan, it is already imbued with my expression. In both of the latter aspects, the word is expressive, but, we repeat, this expression does not inhere in the word itself. It originates at the point of contact between the word and actual reality, under the conditions of that real situation articulated by the individual utterance. (ebd., S. 88)

Bachtins Begriff der Sprechkommunikation beleuchtet, in strenger Abgrenzung zur strukturalistischen Linguistik, die mit ihrer „langue“ als Zeichensystem die Darstellungsfunktion der Sprache analysiert, ganz im Sinne von von Humboldt, die Ausdrucks- und somit Verständigungsfunktion der Kommunikation. Er betont das Verstehen dabei, entsprechend der Basisdifferenzierung einer verstehenden Soziologie, als intersubjektiven Interaktionsprozess zwischen jeweils mit subjektivem Sinn ausgestatteten Individuen. Das Wort der „langue“ bilde nur eine von drei Existenzformen - und dabei die nichtssagendste - ab, wohingegen das Wort noch in zwei weiteren Formen, nämlich für Ego und Alter Ego, existiere. In diesen beiden Formen weise es jeweils Ausdruck auf, nämlich den gemeinten Sinn der Sprechenden bzw. der Verstehenden. Dieser Sinn käme aber stets nur in situ in die Welt, dort nämlich, wo es unter den Bedingungen einer gegebenen Situation in Kontakt mit der Wirklichkeit trete. Besonders kritikwürdig erscheint 
ihm vor dem Hintergrund dieses dialogisch-verstehenden Sprachbegriffs, dass die Linguistik das Sprechen als einsamen Prozess konzipiere, wodurch die Rolle der Zuhörenden sich fälschlicherweise als Passivität darstelle (ebd., S. 69).

Bachtin dagegen verdeutlicht, dass jegliche Äußerung zu jedem Zeitpunkt in der Sprechkommunikation eine Reaktion hervorzurufen in der Lage sei und dass dies sogar auch dann gelte, wenn die Sprechsituation unmittelbare Reaktionen nicht zulasse (ebd.). So würden Äußerungen - mittelbar oder unmittelbar, ausgesprochen oder nicht - stets Folgehandlungen, Sprechakte wie Zustimmung, Ablehnung, Befolgung, Widersetzung etc. nach sich ziehen (ebd.; auch (Volosinov 1973, 85, Collins 1998, 7, J. Berger 2003[1903])). Zudem würden Äußerungen auch bereits darauf hin getätigt, um derlei Reaktionen hervorzurufen und seien daher bereits entsprechend vorentworfen bzw. ausgewählt:

An essential (constitutive) marker of the utterance is its quality of being directed to
someone, its addressivity. As distinct from the signifying units of a language - words
and sentences - that are impersonal, belonging to nobody and addressed to nobody,
the utterance has both an author (and, consequently, expression, which we have
already discussed) and an addressee. This addressee can be an immediate participant-
interlocutor in an everyday dialogue, a differentiated collective of specialists in some
particular area of cultural communication, a more or less differentiated public, ethnic
group, contemporaries, like-minded people, opponents and enemies, a subordinare, a
superior, someone who is lower, higher, familiar, foreign, and so forth. And it can also
be an indefinite, unconcretized other (with various kinds of monological utterances of
an emotional type). (Bakhtin 1986[1952], 95)

Die Zuhörenden, die Adressat/-innen des jeweiligen Sprechens, die - wie die Adressierenden selbst - situationsbezogen in Rollen typisch erfasst werden können (z. B. als Freunde, Gegner, Feinde etc.), sind stets von Bedeutung für jegliche Äußerung, eben weil sie mit der Äußerung adressiert werden: Sei es indem sie das Gehörte (oder Gelesene) selbst zum Anlass einer Äußerung nehmen können, sei es, weil sie das Aufgenommene in späteren Äußerungen wieder aufgreifen, weil sie eine Anschlusshandlung vollziehen können, die in einer Erfüllungsbeziehung zu der vorangegangenen Äußerung steht oder schlicht, weil sie im Bewusstsein der Äußernden die Kommunikationstriade vervollständigen. Dabei sei, so Bachtin, die Äußerung und mit ihr das Thema, der sprachliche Stil sowie die Kompositionsstruktur, stets abhängig von der Situation, in der sie getätigt würde, sodass typische Situationen typische Äußerungen nach sich zögen, die sich durch ein typisches Thema, eine typische Struktur sowie einen typischen Stil auszeichneten. In diesem Kontext spricht Bachtin schließlich von Sprechgattungen (speech 
genres). Unter diesem Begriff fasst er verfestigte Formen typischer Äußerungen, die sich so klassifizieren und mit typischen Situationen ihres Auftretens in Verbindung setzen lassen:

\begin{abstract}
A speech genre is not a form of language, but a typical form of utterance; as such the genre also includes a certain typical kind of expression that inheres in it. In the genre the word acquires a particular typical expression. Genres correspond to typical situations of speech communication; typical themes, and, consequently, also to particular contacts between the meanings of words and actual concrete reality under certain typical circumstances. (Bakhtin 1986[1952], 87)
\end{abstract}

Gattungen sind nach Bachtin also typische Formen von Äußerungen. Sie beinhalten einen bestimmten typischen Ausdruck und entsprechende sprachliche Stile, die themenbezogen dem entsprechenden Ausdruck dienen. In diesem Kontext differenziert Bachtin, entsprechend der Unterscheidung zwischen äußeren und inneren Determinanten der Sprechakte bei Luckmann, zwischen generischen (generic) und individuellen (individual) Stilen des Sprechens.

Während der generische Stil in erster Linie mit der Situation korrespondiert und die Sprechkommunikation nach außen, im Sinne eines typischen Ausdrucks, situationsangemessen rahmt, dient der individuelle Stil vor allem der individuellen Ausdrucksfunktion des Sprechens, der Entäußerung des Innen: Im individuellen Stil drückt die Sprecher/-in sich selbst, ihre Gedanken, Wünsche, Vorstellungen, Ideen etc. aus. Die Realisierung dieses individuellen Ausdrucks sei dabei davon abhängig, wie vertraut die Sprecher/-in mit der entsprechenden Gattung sei (ebd., S. 80):

The better our command of genres, the more freely we employ them, the more fully and clearly we reveal our own individuality in them (where this is possible and necessary), the more flexibly and precisely we reflect the unrepeatable situation of communication-in a word, the more perfectly we implement our free speech plan. (ebd.)

Bachtin weist aber auch darauf hin, dass nicht jede Gattung zum freien Ausdruck geeignet ist (ebd., S. 63): Das durch diese Differenz aufgespannte Kontinuum, das uns ebenfalls bei Luckmann begegnet, bewegt sich bei Bachtin zwischen künstlerischen Gattungen einerseits, die ja ausdrücklich für den individuellen Ausdruck geschaffen sind, und andererseits z. B. dem militärischen Befehl bzw. anderen stark formalisierten Gattungen, die kaum oder keinen individuellen Ausdruck erlauben. Hier wird der basale Zusammenhang zwischen Bachtins Sprechkommunikation und der sozialen Situation offensichtlich: Der Vortrag einer romantischen 
Liebesbeschwörung ist nicht nur sprachlich von der Erteilung eines militärischen Befehls klar zu unterscheiden. Die Situation selbst, in der die jeweiligen Äußerungen getätigt werden, trennt i. d. R. Welten. (Aber auch hier gilt es, das Sprechen in situ zu betrachten, denn in Abhängigkeit von dem individuellen Ausdrucksvermögen der Sprecher/-in bzw. davon, wie geübt sie oder er in der Anwendung von sprachlichem Ausdruck ist, lassen sich auch militärische Situationen durch die Rezitation oder freie Improvisation von Liebesversen konterkarieren, während es denkbar ist, dass auch romantische Situationen durch die Erteilung militärischer Befehle an Heiterkeit gewinnen können.)

Bachtin verdeutlicht, dass Sprechen auf das engste mit der erprobten Anwendung erlernter typischer Ausdrücke und daher mit Gattungen verknüpft sei. Nicht nur wann bestimmte Äußerungen getätigt werden, sondern auch im Kontext welcher anderen Ausdrücke, stellt sich bei Bachtin als hochgradig konventionalisiert heraus. So erweist sich Sprechen als die fortgesetzte Aneinanderreihung von sprachlichen Äußerungen, in denen nicht selten - wie man mit Helga Kotthoff $(1999,37)$ sagen könnte - Gattungsverschachtelungen vorliegen. Bachtin unterscheidet in diesem Kontext zwischen primären, d. h. einfachen Gattungen und sekundären, also komplexeren Gattungen (Bakhtin 1986[1952], 61 f.). So meint er z. B. mit Hinblick auf wissenschaftliche Gattungen, dass diese - wie andere komplexere Formen - einfachere Genres aufsögen und verdauten (,,absorb and digest"), die sich in alltäglichen Umgangsformen entwickelt hätten. So kann die Begrüßung, als einfache kommunikative Form, sowohl als eigenständige (primäre oder einfache) Gattung als auch als Bestandteil einer komplexeren Form, wie dem Vortrag, betrachtet werden, die ihrerseits eine (sekundäre oder komplexe) Gattung darstellt.

Bei Bachtin erweist sich Sprechkommunikation so - in toto - als Sprechen in Gattungen, wobei die Freiheit des Ausdrucks (speech will) i. d. R., neben dem individuellen Stil, der durch die gewählte Gattung begrenzt ist, in der Auswahlmöglichkeit spezifischer Gattungen überhaupt zu betrachten ist:

The speaker's speech will is manifested primarily in the choice of a particular speech genre. [...] We speak only in definite speech genres, that is, all our utterances have definite and relatively stable typical forms of construction of the whole. (ebd., S. 78)

Mit seiner Behauptung der Gattungsförmigkeit sämtlicher Sprechkommunikation, die er damit erläutert, dass wir Sprechen in der Praxis des Sprechens selbst erlernten und dabei, mit den Lauten und Worten zugleich ganze Phrasen, spezifische Ausdrucksweisen, Stile, insbesondere typische Konstruktionsweisen des individuellen Ausdrucks etc. übernehmen würden, geht Bachtin deutlich über das 
Programm der GA hinaus. Während deren Vertreter/-innen zumeist betonen, dass nicht jedes Sprechen in Gattungen aufginge (Luckmann, 1986, 201) (Günthner und Knoblauch 1994, 699), nicht einmal sein größter Teil, meint Bachtin, dass alle Äußerungen stets einer spezifischen Gattung zugehörten, deren Anwendung wir in der Kindheit ebenso unreflektiert erlernten wie unseren Sprachgebrauch überhaupt. Die Ubiquität der Gattungen zeige sich z. B. daran, dass man stets bereits nach wenigen Worten des Gegenübers eine Vorstellung von dessen Vorentwurf seiner Kommunikation habe und einschätzen könne, worin die eigene Rolle im Rahmen der Äußerung bestehe und außerdem - maßgeblich anhand der Struktur (z. B. Prä-, Haupt- und Postsequenz) - erkennen könne, wie lang die Äußerung sich in etwa erstrecken werde etc. (Bakhtin 1986[1952], 79). In diesem Sinn würde die allgemeine Gattungsförmigkeit der Kommunikation eine wichtige Funktion im Sinne ihrer primären Bestimmung als Verständigungsmittel besitzen. Dass Sprache tatsächlich diese implizite Anzeigefunktion besitzt, ist später vor allem in der ethnomethodologischen Konversationsanalyse thematisiert worden (Abschnitt 3.1.4).

Bachtins Thesen, trotz der allgemeinen Gattungsförmigkeit des Sprechens, die er im Rahmen des von ihm gesetzten Begriffs der Gattung (m. E. zu Recht) behauptet, erweisen sich als anschlussfähig an Luckmanns Sprachsoziologie und für dessen spätere GA. Viele seiner Grundannahmen sind auch aus der verstehenden Soziologie bzw. der Wissenssoziologie und dem SoKo bekannt. Hier wie dort gilt die Bedeutung des subjektiven Bewusstseins für die Analyse: Auch Bachtin war ein ausdrücklicher Kritiker des Behaviorismus. Hier wie dort wird dabei aber auch deutlich, dass das konstitutionslogische Subjekt nicht Anlass für Subjektivismus bietet. Im Gegenteil: Während Schütz betont, dass das Wort den Menschen von seiner Subjektivität scheidet und die Strukturen der Lebenswelt den Einzelnen auferlegt seien, verdeutlicht die Wissenssoziologie, dass die Wirklichkeit maßgeblich auf dem basiere, was in gesellschaftlichen Wissensvorräten abgelegt sei (Abschnitt 2.1). Was bei Schütz im Wort und bei Berger und Luckmann im Wissen objektiviert ist, nämlich die Rahmen der Wirklichkeitsbestimmung, und schon hier auf das engste mit Sprache verknüpft ist, findet sich bei Bachtin in den Äußerungsformen, d. h. in den Sprechgattungen selbst.

Bachtins Gattungen erweisen sich damit als das, womit sie auch in der GA (hinsichtlich ihrer Funktion) ausdrücklich gleichgesetzt werden: soziale Institutionen. Die Individualität bzw. Subjektivität des Ausdrucks liegen daher ganz im Bereich dessen, was von mir zuvor, in Hinblick auf das Wissen, Permutation genannt wurde. Grundressource des subjektiven Wissens einer- und des subjektiven Ausdrucks andererseits ist stets das verfestigte Soziale - Wissen und seine 
Vermittlungsformen, wobei beides im Phänomen der Kommunikation untrennbar miteinander verwoben scheint. ${ }^{6}$

Obgleich ich Bachtins Soziologismus der Sprechkommunikation zustimme, so ist bei aller Genialität seiner Ausführungen eines doch nicht zu übersehen: Bachtin war nicht Soziologe. Im vorliegenden Kontext ist diese Bemerkung von Relevanz: Denn zwar entwirft Bachtin sein Gattungskonzept, das auf seinem Begriff der Äußerung basiert und sich von der strukturalistischen Linguistik abzugrenzen bemüht ist, streng im Kontext der sozialen Situation und anhand des Dialogs, betont dabei ausdrücklich die Rolle der anderen, der Kommunikationsgeschichte sowie weiterer sozial abgeleiteter Bedingtheiten. Jedoch fehlt ihm m. E. ein genuin soziologisches Denken, um der Bedeutung der Sozialität des kommunikativen Handelns in seiner Sprechkommunikation begrifflich vollständig gerecht zu werden. Dies wird insbesondere an der Wahl seiner Grundeinheit, der Äußerung (des speech subjects), deutlich. Die Pointe der soziologischen Betrachtung liegt darin, dass - wie Simmel bereits ausführte - die kleinste Einheit soziologischer Betrachtung die Dyade ist, die Beziehung also, die das einzelne Subjekt überschreitet und die Wechselwirkung zwischen mindestens zwei Subjekten entfaltet (Interaktion). In diesem Sinn hat Bachtin - konversationsanalytisch gesprochen - zwar den Turn als intersubjektiv nachvollziehbare Markierung des Endes von Äußerungen erkannt. Den nächsten, soziologisch weit relevanteren Schritt, hin zur Sequenz als kleinste Sinneinheit der gesprochenen Sprache (bzw. der Kommunikation), hat er allerdings noch nicht vollzogen. Erst in der Sequenz erweist sich aber speech communication als intersubjektives Phänomen und wechselwirkender talk in interaction (Schegloff 1991, Rendle-Short 2006) - was bei Bachtin zwar bereits angesprochen ist, aber noch nicht begrifflich erfasst werden kann. Nicht zuletzt aus diesem Grund ist die CA von großer Bedeutung für die GA, zu der sie auf Umwegen u. a. die ethnomethodologisch informierte Sequenzanalyse beisteuert.

\footnotetext{
${ }^{6}$ Kommunikation stellt daher die Klaviatur bereit, die einerseits der individuellen Erkenntnis und andererseits dem individuellen Ausdruck zur Verfügung steht. Die Kreativität, die notwendig ist, um auf dieser Grundlage Neues zu entdecken und auszudrücken, ist davon abhängig, wie virtuos man diese Klaviatur zu bedienen weiß. Im ,Spiel' können einerseits eingeübte Formen reproduziert und anderseits, z. B. in Improvisation, neue Begriffe, Ausdrucksweisen, Phrasen oder Gattungen in Rekombination bereits bekannter Elemente entwickelt werden.
} 


\subsubsection{Die ethnomethodologische Konversationsanalyse}

In einem Vortrag 2017 in Bayreuth, anlässlich eines Treffens des Nachwuchsnetzwerks Videoanalyse, machte Bernt Schnettler allerdings darauf aufmerksam, dass Luckmann skeptisch gewesen sei, was die CA betraf. Der Situationalismus der Ethnomethodologie sei ihm „unsoziologisch“ erschienen: Luckmanns Ansatz ist, wie bereits deutlich gemacht wurde, der Erforschung von Handeln und Institutionen verschrieben. Seine Soziologie, die er mit Berger und Schütz ausarbeitete, erklärt Ersteres vor dem Hintergrund der Letzteren (und im Sinne einer Dialektik: vice versa) und ist daher mit einigen der wesentlichen Postulate der Ethnomethodologie unvereinbar. ${ }^{7}$ Die CA ist schließlich erst dann als Jörg Bergmann, der bei den Ethnomethodologen Harvey Sacks und Emanuel Schegloff studiert hatte, Luckmanns Mitarbeiter wurde, von Luckmann aufgenommen worden (Abschnitt 3.2.3). Sie erfuhr daher auch erst im Rahmen der GA allmählich Berücksichtigung und damit später als die Soziolinguistik, die Luckmann bereits für seine Sociology of Language (1975) rezipierte. CA stellt die minutiöse Analyse von sprachlichen Handlungsabläufen (Bergmann 1981, 14) dar, die von Garfinkel-Schüler/-innen wie Sacks mit dem Ziel entwickelt wurde, die Ethnomethoden zu bestimmen, mittels derer Sprecher/-innen die Geordnetheit ihrer Kommunikation erzeugen. ${ }^{8}$ Bergmann (ebd., S. 21 f.) gliedert die CA in drei Teilschritte: Erstens gelte es die Geordnetheit in der scheinbar ungeordneten Kommunikation zu entdecken. Audiodaten machten es dabei leicht möglich, entsprechende Ordnungen tatsächlich aufzufinden (Sacks, Schegloff und Jefferson 1974, 699). Zweitens werde geprüft, für welches Problem die gefundene Ordnung eine Lösung darstelle. Schließlich werde drittens in den erhobenen Audiodaten nach den Ethnomethoden gesucht, mittels derer die Ordnung hergestellt werde. Das übergeordnete Prinzip dieser Methoden stellt das „turn-taking-system“ (ebd.)

\footnotetext{
${ }^{7}$ In der , orthodoxen ‘ Form (Lynch 1999) ist die Ethnomethodologie kaum als Soziologie zu begreifen. Dies schmälert nicht den Beitrag, den sie, nicht zuletzt auf Grundlage von Schütz, zur Entwicklung des interpretativen Paradigmas und in Bezug auf die GA, geleistet hat. Die ethnomethodologische Grundhaltung verdeutlicht aber u. a., wieso die Ethnographie der Kommunikation für die Praxeolog/-innen interessant erscheinen musste und wieso sie den Weg für eine eigene ethnomethodologische Sprachforschung, die CA, mit bereitete (Sacks et al. 1974).

${ }^{8}$ Dieser Anspruch der CA wurde erst durch die Einführung des Tonbands in die Soziologie ermöglicht: „Die Rigorosität und der Detailanspruch dieses Programms machten es erforderlich, eine Technik einzusetzen, die es ermöglichte [...] Handlungen zum Zweck ihrer Dokumentation gleichsam einzufrieren, d. h. so zu fixieren, dass sie für die Analyse beliebig oft reproduzierbar werden konnten. Im Tonband - und später im Videogerät - stand eine solche flexible und umstandslos handhabbare Technik zur Verfügung. " (Bergmann 1981, 15).
} 
dar. Es dient, als lokal regulativer Apparat (Bergmann 1981, 25), als lokales Management (ebd., S. 29), der Organisation sprachlicher Interaktion. Dabei stellt sich der „turn“, bei Bachtin: „change of speech subjects“ (Bakhtin 1986[1952], 76), bei Sacks et al. als interaktives Objekt (1974, 726 f.) heraus, das Auslöser von etwas größerem ist als die Äußerung bei Bachtin, nämlich der Sequenz.

Unter Paarsequenzen (adjacency pairs) versteht man in der CA z. B. Frage und Antwort. Dabei gilt,

dass eine Äußerung, die als Erster Teil eines Äußerungspaares wahrgenommen wird, eine normative Erwartung aufbaut im Hinblick auf die vom Gesprächspartner zu formulierende Nachfolgeäußerung. (Bergmann 1988b, 18 f.)

Daher kann der zweite Teil einer Paarsequenz nicht beliebig sein, sondern muss sich sinnhaft auf die normative Erwartung beziehen lassen, die in ihrem ersten Teil zum Ausdruck kommt. Statt mit einer Antwort kann man einer Frage natürlich auch mit einer Gegenfrage oder einem Exkurs begegnen; der erste Teil einer Paarsequenz kann auch durch eine kurze Formel oder eine längere Einführung begonnen werden und die Antwort kann, statt sich auf Fakten zu beschränken, zu einer längeren Äußerung ausholen etc. So lassen sich Paarsequenzen tatsächlich beliebig durch sog. Einschub-, Prä- und Nach-Sequenzen ausweiten. (Der Redezugwechsel als Typ sozialer Organisation in ,Sprech-Austausch-Systemen * ist daher "one of the hardest lessons for children under five years to learn" (Sacks, Schegloff und Jefferson 1974, 698).)

Das Modell der CA, das anhand der Analyse von Audiodaten natürlicher Kommunikation entwickelt wurde, basiert auf zwei Komponenten, wobei die Letztere sich durch drei fundamentale Regeln auszeichnet: Zunächst die Turnkonstruierende Komponente - hiermit bezeichnet die CA das, was Bachtin Äußerung, Hymes und Luckmann Sprechakt nennen: nämlich Absätze, Sätze oder einzelne Worte (unit-types) gesprochener Sprache. Sie beinhalten zum einen den (generischen und individuellen) Ausdruck, geben den an der Kommunikation Beteiligten zugleich aber auch wichtige Hinweise auf mögliche Transitpassagen, Momente im Fluss des Sprechens, die einen Redezugwechsel ermöglichen. Hier wird die zweite Komponente von Sprech-Austausch-Systemen relevant, die Turn-Zuweisungskomponente: Damit bezeichnet die CA Ethnomethoden der interaktiven Selektion der nächsten Sprecher/-in in Konversationen. In den Audiodaten, so Sacks et al. (1974), zeigten sich folgende, regelhafte Varianten: Erstens, entweder die gegenwärtige Sprecher/-in wähle die nächste Sprecher/-in, indem sie sie oder ihn z. B. direkt anspreche, zur Antwort auffordere etc. Zweitens, die nächste Sprecher/-in wähle sich selbst, indem sie oder er z. B. eine Pause 
nutze oder den Redefluss der gegenwärtigen Sprecher/-in unterbreche etc. Oder, drittens, die gegenwärtige Sprecher/-in wähle sich, im Sinn eines fortgesetzten Sprechens, selbst zur nächsten Sprecher/-in. Zweck dieser (zumeist) informellen Regeln sei es, Überlappungen und Lücken zu minimieren (ebd., S. 705), die ohne sie nicht zu vermeiden wären. Ein geordnetes Sprechen in Interaktion (RendleShort 2006, 2 f. und passim) wäre ohne diese Ethnomethoden des Sprechens nicht möglich.

Auf Grundlage ihrer Empirie stellen Sacks et al. fest, dass dem informellen Alltagsgespräch unter anderen Sprech-Austausch-Systemen (ebd., S. 729 ff.) die besondere Rolle zukäme, die Basisform aller Formen von in Kopräsenz gesprochener Sprache darzustellen und dass andere Formen, Abstufungen zwischen stark, weniger stark und kaum formalisierten Sprechereignissen, die auch Bachtin (1986[1952]) und Luckmann (1975) thematisieren, entsprechend Modulationen der alltäglichen Konversation seien (Sacks, Schegloff und Jefferson 1974, 730). Sprech-Austausch-Systeme, wie sie die CA betrachtet, umfassen somit das kontinuierliche Repertoire von der Alltagskonversation (lokale Allokation von Redezügen, unbestimmte Anzahl von Sprecher/-innen, offene Redezuglänge) bis hin zu z. B. wissenschaftlichen Vorträgen (Präallokation von Redezügen, Begrenzung der Sprecher/-in, festgelegte Redezuglänge). Dabei betont die CA, dass alle Sprech-Austausch-Systeme lokal organisiert seien, ,all the operations are local“ (ebd., S. 725). Selbst wenn sie formalen Charakter besäßen, müssten sie situativ durch die Teilnehmenden koordiniert werden. Aufgrund dieses Erfordernisses seien sie durch die wechselseitige Aufmerksamkeit der Teilnehmer/-innen charakterisiert (ebd., S. 726). Hier zeigt sich die Beobachtung einfordernde Anzeigefunktion von Äußerungen, die bereits Bachtin anspricht und die für soziologische Analysen eine besondere Relevanz besitzt (ebd.): Methodologisch entscheidend dafür ist die Reflexivität (Tuma, Schnettler und Knoblauch 2013, 90) der Ethnomethoden als ,accounting practices“ (Garfinkel 1984[1967], 1): ,[T] he activities whereby members produce and manage settings of everyday affairs are identical with members' procedures for making those settings account-able." (ebd.)

Die Hinweise, die sich Kommunizierende in ihrem (kommunikativen) ,Anzeige-Handeln' geben, um ihren Alltag (kommunikativ) handelnd zu bewältigen und sich dabei zu koordinieren, lassen sich auch für die soziologische Analyse auswerten. Hierin liegt die Pointe der CA bzw. der Ethnomethodologie, die ausschließlich diese Ethnomethoden als „Tutorials“ der soziologischen Erkenntnis anerkennt (Lynch 1999, 226 f.). Menschen liefern fortlaufend Hinweise darauf, in welcher Situation sie sich gemeinsam befinden, wer welche Rolle übernimmt, welche Interessen verfolgt, was von Belang und was derzeit 
ohne Relevanz ist etc. Die alltägliche Bewerkstelligung von gesellschaftlicher Wirklichkeit basiert, laut Garfinkel, maßgeblich auf entsprechendem wechselseitigem Anzeige-Handeln und der Interpretation des dabei ausgedrückten Sinns. Eben dieses Prinzip im Rahmen ihrer Sequenzanalyse für die soziologische Forschung geöffnet und schematisiert zu haben, ist das große Verdienst der CA für die empirische Sozialforschung. Entsprechend machte die Sequenzanalyse sowohl in der GA als auch in der aus ihr entwickelten Videographie Karriere (siehe Abschnitt 1.2.3.1), wohingegen andere Postulate der Ethnomethodologie sich in der Soziologie als weniger anschlussfähig erwiesen.

\section{Exkurs: CA-verwandte Ansätze}

Nicht zu den Vorläufern der wissenssoziologischen GA (noch zu ihren Nachfolgern) zählen zahlreiche kommunikationsanalytische Ansätze, die der CA verpflichtet (ethnomethodologische Kommunikationsforschung) sind oder ihrerseits in der CA stark rezipiert wurden (insbesondere Gestenforschung). Obgleich ich diese Arbeiten nicht systematisch berücksichtigen werde, da sie Kommunikationsformen nicht als Gattungen, das heißt in ihrem vollen Kontext auf Makro- bzw. Mesoebene betrachten können oder wollen, müssen sie an dieser Stelle genannt werden, nicht zuletzt vor dem Hintergrund ihrer großen Bedeutung für die soziologische Mikroanalyse im Allgemeinen und die entsprechende Methodenentwicklung. Hierzu zählen die Pionierarbeiten zu (non-)verbaler Kommunikation in der CA, deren Erkenntnisse prominent auch in die Entwicklung des KoKo bzw. der kommunikationssoziologischen GA miteingeflossen sind (Knoblauch 2017, 51).

$\mathrm{Zu}$ nennen sind in diesem Kontext insbesondere die Arbeiten von Christian Heath (1984a, 1984b, 1986) und Charles Goodwin $(1979,1981)$, in deren Kontext gleichzeitig mit der mikroanalytischen Fokussierung auch die visuelle Methode in der qualitativen Forschung etabliert wurde (Goodwin 1979, Heath 1984a). Diese Arbeiten sind ihrerseits, bzgl. ihrer mikrosoziologischen Fokussierung des nonverbalen Ausdrucks in ,natürlichen Situationen' (Goodwin 1981, 33 f.) sowie der Entwicklung audio-visueller Analyseverfahren, stark von der Gestenforschung, insbesondere von den Arbeiten Adam Kendons, beeinflusst (Heath 1992, 705).

Kendon war es, der erstmals die Bedeutung von Blicken (1967) und Bewegungen (1970) im Sinne von ,visual action“ (Kendon 2004) systematisch in den Fokus der Analyse von Face-to-face-Kommunikation setzte, wobei er bereits sehr früh Filmaufzeichnungen verwendete $(1967,24 \text { f. })^{9}$. An Kendon wiederum schließen

\footnotetext{
${ }^{9}$ Kendon seinerseits nennt Simmel als frühen soziologischen Vorläufer seiner Blickstudien (1967, $22 \mathrm{ff})$.
} 
neuere konversationsanalytisch informierte Arbeiten der linguistischen Anthropologie an, allen voran von Elinor Ochs, Sally Jacoby, Patrick Gonzales und Johanna Rendle-Short. Die entsprechenden Arbeiten beschäftigen sich mit „shop“ und/oder ,institutional talk“ in der Wissenschaft. Während Ochs et al. dabei insbesondere die Verwendung von Visualisierungen (Ochs, Jacoby und Gonzales 1994, Ochs, Gonzales und Jacoby 1996) und die Auswirkung von Zeitlichkeit (Ochs und Jacoby 1997) in der Kommunikation einer Gruppe von Physiker/-innen beobachten und analysieren, ist Rendle-Shorts Monographie zum ,academic talk“ (2006) maßgeblich auf die Funktionsweise erfolgreicher Wissenskommunikation in einem interdisziplinären Institutskolloquium ausgerichtet.

Während diese Ansätze einen ähnlichen Gegenstand und die Fokussierung der Kommunikation als Grundlage für den interaktionalen Verstehensprozess mit meiner eigenen Forschung, meinen Vorannahmen und Grundbegriffen, teilen, bestehen bzgl. der theoretischen Verortung dieser Arbeiten erhebliche Unterschiede, sodass ich sie als Inspirationen für Teilaspekte meiner eigenen Arbeit herangezogen habe, aber nicht an sie anschließe. Deutlich wird der maßgebliche Unterschied z. B. in der Monografie von Rendle-Short (2006) hinsichtlich ihrer Verpflichtung gegenüber dem zuvor erläuterten, ethnomethodologischen Paradigma': Vor dem Hintergrund dieser Beschränkung auf die Situation und das Anzeigeverhalten der Feldteilnehmer/-innen gelingt es ihr m. E. nicht, die von ihr beobachtete Kommunikation mit dem übergeordneten institutionellen Kontext zu verknüpfen. Dies ist deshalb erwähnenswert, weil sie diesen Anspruch durchaus formuliert (RendleShort 2006, 3). Gleichzeitig geht sie aber in ihren empirischen Analysen tatsächlich nicht über die Situation hinaus. So verbleibt ihre Arbeit zum ,academic talk“ m. E. auf der Ebene einer elaborierten klassischen CA-Analyse, wobei sie eine spezifische, in der Wissenschaft angesiedelte Kommunikationsform erforscht, ohne diese dabei strukturell mit dem übersituativen Kontext zu verknüpfen. Die Arbeiten von Ochs et al. wiederum sind sehr stark von der Linguistik geprägt und fokussieren vor allem sprachliche bzw. syntaktische und andere Aspekte des Sprechens in Interaktion, die für meine eigene Arbeit nicht als eigenständiger Gegenstand relevant sind. Außerdem möchte ich den angestellten Schlussfolgerung an vielen Stellen nicht folgen. ${ }^{10}$

Nichtsdestotrotz bestätigen die empirischen Befunde von Ochs et al. und Rendle-Short viele meiner eigenen Forschungsergebnisse, die auf den Ebenen der

${ }^{10}$ Z.B. wenn Ochs et al. (Ochs, Jacoby und Gonzales 1994, 170 f.), mit Verweis auf Donna Haraways Cyborgs (Haraway 1991), darauf verweisen, dass die Grenzen zwischen Menschen und Visualisierung verschwämmen. 
Binnenstruktur sowie der situativen Realisierung meines gattungsanalytisch geprägten Forschungsdesigns gelegen sind. Dies gilt insbesondere für die im Rahmen der Analyse von Face-to-face-Kommunikation innerhalb einer Gruppe Physiker/-innen gewonnenen Erkenntnisse, hinsichtlich der engen Verknüpfung von Visualisierung und Erkenntnisgewinn in den Prozessen Herstellung und Benutzung von Visualisierungen in Forschung bzw. Wissenskommunikation (Ochs, Jacoby und Gonzales 1994, 170, Ochs, Gonzales und Jacoby 1996, 359) sowie für die durch Rendle-Shorts Beobachtung eines Institutskolloquiums gewonnenen Einblicke in die performative Herstellung eines ,recipient designs“ (2006, 13 und passim) durch die jeweils Vortragenden sowie die Ubiquität von (digitalen) Visualisierungen (ebd., S. 101) als wesentliches Element ihrer Vortragsweise (,display rule“) (Abschnitt 4.2).

\subsubsection{Die Interaktionsordnung}

Ein weniger , starkes“ Programm als die CA verfolgt Erving Goffman. Die CA, die ihn nicht unmaßgeblich rezipierte, erschien Goffman zu reduktionistisch (Bergmann 1999, 309). Nichtsdestoweniger ist er sowohl für die Ethnomethodologie als auch für die CA (ebd., S. 302) und für Luckmann (Schnettler 2006, 42) von großer Bedeutung: Letzterer rezipierte Goffman im Gegensatz zur Ethnomethodologie oder der CA bereits 1975. Neben den Rede-Weisen (Goffman 2005a) scheint im Rahmen der GA vor allem der bei Goffman zentrale Begriff der Interaktionsordnung relevant. Goffman dachte, dass Soziolog/-innen sich mit der Schnittstelle zwischen Interaktion und sozialer Organisation beschäftigen sollten. Schon mit diesem Postulat ist er weit vom Situationalismus der Ethnomethodologie entfernt und nahe an Luckmann. In seinem 1971 (engl. 1967) erschienenen Buch Interaktionsrituale. Über Verhalten in direkter Kommunikation (Goffman 1971[1967]) schreibt er, auf einen weiten Kommunikationsbegriff rekurrierend (Knoblauch, Leuenberger und Schnettler 2005, 13), sein Ziel sei es, ,direkte Interaktion in alltäglichen Zusammenhängen“ zu untersuchen (Goffman 1971[1967], 7). Dies sei, ganz im Sinne der Soziolinguistik, ,durch gute ethnographische Studien“ (ebd., S. 8) zu erreichen. Im Fokus dabei:

[A]ngefangen bei der kleinsten Einheit, dem flüchtigen Mienenspiel [...] bis hin zu solchen Ereignissen wie wochenlangen Konferenzen, Interaktionsmonstren, die an der äußersten Grenze dessen liegen, was man als soziale Gelegenheit bezeichnen kann. Ein weiteres Ziel ist die Aufdeckung der normativen Ordnung, die innerhalb und zwischen diesen Einheiten herrscht, d.h. die Verhaltensregeln, die es überall gibt, 
wo Leute sind, unabhängig davon, ob es sich um öffentliche, halböffentliche oder private Orte handelt und ob diese unter den Auspizien einer sozialen Gelegenheit oder den lockeren Zwängen eines einfachen routinierten sozialen Rahmens stehen. (ebd.)

In Bezug auf Sprechen in Interaktion stellt Goffman in seiner Arbeit fest, dass dieses auf einem spezifischen System aus „Praktiken, Konventionen und Verfahrensregeln", der normativen Ordnung, basiere, die der Organisation des Sprechens in Interaktion diene (ebd., S. 40 f.). Dieses „System“, die Interaktionsordnung, regele, wann, wo, mit wem und mittels welcher signifikanten Gesten gesprochen und der Status der Beteiligten ausgedrückt werde; worauf der gemeinsame (thematische und visuelle) Aufmerksamkeitsfokus liege, der, ebenso wie die Redezugzuweisung, durch sprachliche und nicht sprachliche Hinweise der Interaktionsteilnehmer/-innen organisiert würde; wie lang die einzelnen Redezüge andauerten; wie mit Pausen und Störungen im Gesprächsfluss, wie mit Dissens umzugehen, wie das Thema der Kommunikation zu wechseln sei etc. Goffman stellt dabei hervor, dass die Regeln des Gesprächs, die sowohl für formale als auch für informelle Interaktionen, wenn auch in unterscheidbarer Explizität, vorliegen würden, nicht Teil des Gesprächsverlaufs selbst seien, sondern „zu einem Gesprächsanlass, zu einer Interaktionsepisode“ (ebd., S. 42) gehörten.

Will man herausfinden, wie diese Konventionen als Leitfaden der Handlung aufrechterhalten werden, findet man Hinweise dafür, die eine funktionale Beziehung zwischen der Struktur des Selbst und der Struktur sprachlicher Interaktion vermuten lassen. (ebd., S. 43)

Die Verbindung zwischen beidem, der Gesprächssituation und ihrer Ordnung, findet Goffman, in Anlehnung an Meads Konzept der Identität, in der Sozialisation des Individuums. In der sozialen Situation, die Goffman (1964, 135) zunächst weit anders als Luckmann $(1975,44)$, nämlich als wechselseitige Wahrnehmung in Kopräsenz (Knoblauch 1994, 34) und nicht in Hinblick auf den Institutionalisierungsgrad definiert, werde an das Selbstbild (image) appelliert, wodurch die Interaktionsteilnehmer/-innen große Sorgfalt darauf verwendeten, sich sozial angemessen $\mathrm{zu}$ verhalten. ${ }^{11}$

Den Kern der Interaktionsordnung bilden soziale Situationen, an denen zwei oder mehr Personen beteiligt sind; hier zeigen sie ihre Aufmerksamkeit und Anteilnahme,

\footnotetext{
${ }^{11}$ Hierdurch ist die soziale Situation - aus Perspektive des SoKo - selbstredend auch bei Goffman sehr wohl hochgradig institutionalisiert.
} 
hier findet die Koordination von Handlungen statt, und hier sind ihre Körper verletzlich (ein für die Ausbildung dieser Ordnung von Goffman immer wieder betonter Aspekt). (ebd., S. 35)

Dabei gilt, wie Goffman in seinem frühen Buch Wir alle spielen Theater. Die Selbstdarstellung im Alltag (2003/1983[eng1.1959]) bereits ausführte, der Schutz des eigenen Selbst(-bildes) ebenso viel wie der Schutz der Selbstbilder der anderen Teilnehmer/-innen. Im Rahmen seiner Grundannahme, ,dass die Selbstdarstellung des einzelnen nach vorgegebenen Regeln und unter vorgegebenen Kontrollen ein notwendiges Prinzip des menschlichen Lebens ist“" (Dahrendorf 2003/1983, VII), behandelt Goffman die sozialen Techniken, die die Stabilisierung dieser Darstellungen ermöglichen. Diese Techniken ähneln dabei stark den Ethnomethoden, die Garfinkel und seine Schule fokussieren. Ganz im Sinne von Garfinkels ,,breaching experiments“ (Garfinkel 1984[1967], 54) betrachtet Goffman zunächst auch typische Störungen der „Inszenierungen“ (2003/1983[engl.1959], 189 ff), um der sonst unmerklich vollzogenen Ordnung auf die Spur zu gelangen ${ }^{12}$ : So analysiert er z. B. den Mangel an Eigenverantwortlichkeit der Darsteller/-innen in Bezug auf ihr Handeln, wie z. B. „unbeabsichtigte Gesten“ aber auch ,unpassendes Eindringen“, die ,peinliche Aufdeckung“, „Fauxpas“ und ,Szenen“, um - vor diesem Hintergrund - zu den Techniken der Eindrucksmanipulation, also den „,Techniken der erfolgreichen Rolleninszenierung“" zu gelangen:

Um Zwischenfälle und die damit verbundene Verlegenheit zu vermeiden, müssen alle Teilnehmer an einer Interaktion ebenso wie die Zuschauer gewisse Eigenschaften besitzen und sie dazu benützen, um die Darstellung zu schützen. (ebd., S. 193)

Unter den Eigenschaften und Maßnahmen der Verteidigung versteht Goffman Techniken oder Ethnomethoden, die er mit Begriffen versieht, die er von seiner berühmt gewordenen Bühnenmetapher aus Wir alle spielen Theater ableitet: „dramaturgische Loyalität“ (z. B. Diskretion), „dramaturgische Disziplin“ (z. B.

12 Garfinkel (1984[1967]) fasste diese Herangehensweise, die zunächst ,Störungen ‘ betrachtet, um so auf die Regeln der Ordnung rückschließen zu können, und die er methodisch anwendete, wie folgt: „Procedurally it is my preference to start with familiar scenes and ask what can be done to make trouble. The operations that one would have to perform, in order to multiply the senseless features of perceived environments; to produce and sustain bewilderment, consternation, and confusion; to produce the socially structured affects of anxiety, shame, guilt, and indignation; and to produce disorganized interaction should tell us something about how the structures of everyday activities are ordinarily and routinely produced and maintained." (S. 37 f.) 
Selbstbeherrschung) sowie die „dramaturgische Sorgfalt“ (z. B. durch „Voraussicht und Planung"). All diese Techniken - und gerade hierin erweisen sie sich als Ethnomethoden, in denen Tun und Anzeigen in eins fallen - zeichnen sich dadurch aus, dass sie wechselseitig angezeigt, dass sie einander kommuniziert werden und den Beteiligten an der Interaktion so eine ständige Bestimmung der Situation, ihrer Umstände und der Regelkonformität des Ablaufs ermöglichen. Dies gilt sowohl für geglückte Inszenierungen als auch für deren Scheitern. Auch „Szenen“ sind in diesem Sinn Techniken der Inszenierung und können etwa dazu dienen, eine ,unerträglich ' gewordene Inszenierung eines anderen zu unterbrechen und die Handlung der fortlaufenden Interaktion neu zu wählen. Die Aufrechterhaltung des Images ist also von Maßnahmen abhängig, die nur z. T. in den Händen der jeweils aktuellen Sprecher/-in liegen. Wie auch Bachtin und die CA betonen, ist das Publikum, d. h. die jeweiligen Adressat/-innen, ebenso an der Kommunikation beteiligt wie die Adressierenden.

Die Adressierenden haben zwar eine Sorgfaltspflicht, vor deren Hintergrund erst Loyalität erwartet werden darf. Dabei sind Alltagsdarsteller/-innen einer „Interaktionsepisode" bzw. einer Äußerung (Bachtin), eines Sprechakts oder einer kommunikativen Gattung (Luckmann), aber, trotz aller Vorbereitung, auch abhängig vom „Takt“ der anderen (ebd., S. 208 ff): Indem diese der „Hinterbühne“ fernblieben, das Selbstbild, die Rolle, des anderen unangetastet ließen - oder sich der Person dahinter nur taktvoll näherten, wie im Fall der räumlichen Annäherung, die durch „Anklopfen oder Hüsteln“ angezeigt werden könne -; indem sie sich uninteressiert geben, wenn sie etwas nicht für die „Vorderbühne“ bestimmtes erhaschen; indem sie „mitspielen“; einen Fauxpas übersehen, eine Entschuldigung akzeptieren; im Sinne eines „geheimen Einvernehmens“ die Fehler der Inszenierung der Darsteller/-in decken; ihr oder ihm gar etwas ,vorspielen“. ${ }^{13}$ In all diesen Fällen erweist sich das Sprechen in sozialen Situationen als Interaktion und damit als die Leistung eines Ensembles und nicht einer einsamen Sprecher/-in.

Sprechereignisse sind bei Goffman daher stets in ein ausgesprochen komplexes Gebilde verwoben, das auf mehr oder minder impliziten Regeln des wechselseitigen Eindrucksmanagements, der Aufrechterhaltung des Images der Beteiligten, mit einem Wort: der Interaktionsordnung beruht, die die „Simplest Systematics

\footnotetext{
${ }^{13}$ Vor dem Hintergrund seiner vielleicht geradezu ,verschwörungstheoretisch ‘ anmutenden Ausführungen erläutert Goffman allerdings, dass sein Blick hinter die Kulissen der ,Darsteller/-innen“ nicht mit der Aufdeckung eines Geheimnisses gleichzusetzen sei (2003/1983[engl.1959], 213). Die „Charaktermaske“ diene dem Menschen als schützende Verdinglichung. Sie sei darum aber nicht weniger authentisch als das Wesen, das darauf angewiesen ist, sich hinter ihr zu verbergen.
} 
for the Organization of Turn Taking for Conversation" (Sacks, Schegloff und Jefferson 1974) in weitem Umfang überschreitet. Bergmann sieht darin vermutlich nicht zu Unrecht das besondere Charakteristikum von Goffmans Arbeit:

GOFFMANs gesprächssoziologische Untersuchungen sind von dem fortwährenden Bemühen gekennzeichnet, gegen die trivialisierenden Vereinfachungen und Reduktionen, die er in der Soziolinguistik, in der Sprachphilosophie und ebenso in der Konversationsanalyse entdeckt zu haben glaubt, hervorzukehren, daß die realen Vorgänge der sprachlichen Interaktion sehr viel dynamischer organisiert und in sich gebrochener sind, als dies mit deren verarmten Begriffsinstrumentarien zu erfassen ist. (Bergmann 1991, 317)

In seinem letzten Buch Forms of Talk (1981) wendet Goffman sich vor diesem Hintergrund u. a. dem Vortrag (lecture) zu, wobei er verdeutlicht, dass auch dieses institutionalisierte Sprechereignis, ganz im Sinne der CA, eine hochgradig lokal organisierte Form der wechselseitigen Koordination erfordere. Seine Perspektive, die er aus Sicht der normativen Rollenerwartungen der Interaktionsteilnehmenden gewinnt, verdeutlicht dabei, dass die Interaktionsordnung auch dann von großer Relevanz ist, wenn es vordergründig , nur' um Wissensvermittlung gehen soll. Damit stellt er die formale Form in große Nähe zu den Alltagsformen der Kommunikation, wie dies vor ihm die CA und auch Bachtin getan haben. Die Grundstruktur der Kommunikation scheint stets Elemente ihrer Alltagsformen zu konservieren (Goffman 1974, 498). ${ }^{14}$

Den Vortrag betrachtet Goffman als eine ,institutionalisierte Form, das Wort zu ergreifen“ (2005b, 9) oder - in Anlehnung an Hymes - als „Sprechereignis“ (ebd., S. 11), mit dem die Absicht verfolgt werde, ,ruhiges Verstehen“ (ebd.) zu erzeugen. Für die Darbietung der Sprecher/-in wählt er, in Anlehnung an seine Bühnenmetapher aus Wir alle spielen Theater, den Begriff der Performanz (performance), den Knoblauch im KoKo zentral aufgreift (Abschnitt 2.2.1). Die Sprecher/-in eines Vortrags selbst gilt Goffman im Sinne seiner Bühnenmetapher

${ }^{14}$ An dieser Stelle muss darauf hingewiesen werden, dass auch der SoKo, aufbauend auf Schütz (1971), davon ausgeht, dass der Alltag, ,die Wirklichkeit par excellence“, „die oberste Wirklichkeit“ darstellt, die sämtliche ,Sinnprovinzen“ vollständig umgibt und zu der wir stets und unwillkürlich zurückkehren, nachdem wir in eine der mannigfaltigen anderen Wirklichkeiten - z. B. die theoretische Einstellung - eingetaucht waren (Berger und Luckmann 1986/1969[engl. 1966], 24 ff). In diesem Sinn stellt der Alltag und unsere dort erlernten Formen des Umgangs und der Kommunikation selbstredend auch die Blaupause für alle weiteren Formen des Umgangs und der Kommunikation dar, die sich automatisch einstellt, wenn ausdrücklich anders - d. h. nicht-alltäglich - gehandelt bzw. kommuniziert werden soll (Latour 1990, 22). 
weiterhin als Darsteller/-in (performer), die während ihrer Performanz, im Rahmen einer sozialen Situation (Interaktionsepisode), einem kopräsenten Publikum begegnet.

Ein Vortrag verfolgt [...] das Ziel, das Publikum, den Hörsaal, den Anlass und den Redner vergessen zu lassen und sie stattdessen mitten in den Gegenstand zu führen, dem der Vortrag gewidmet ist. (ebd., S. 11)

Wie die CA (und zuvor bereits Bachtin) setzt auch Goffman die Form des Vortrags trennscharf von weniger stark formalisierten Gesprächssituationen wie der Konversation ab. Vorträge erforderten (auch) eine institutionell-organisatorische Basis. So ließen sich z. B. Formate wie der einmalige Vortrag von Vortragsserien (ebd., S. 13) unterscheiden. In diesem Kontext hebt er hervor, dass ,[e]inmalige öffentliche Vorträge eines Sprechers, der ansonsten für das Publikum nicht zugänglich ist (und vor einem Publikum, das ihm normalerweise nicht zugänglich ist)“, häufig in eine „Zeremonie“ eingebettet seien (ebd.). Vor dem institutionellorganisatorischen Hintergrund des Vortrags würden dabei zugleich drei Dinge ,zelebriert": Die Sprecher/-in, das Thema sowie die ausrichtende Organisation (ebd., S. 14). Damit macht Goffman auf das Verhältnis aufmerksam, dass sich zwischen dem Vortrag als „Form der Wissensvermittlung“ einerseits und seiner Funktion als wechselseitige Legitimierung von Sprecher/-innen und Institutionen andererseits aufspannt: „Offensichtlich bedeutet Werben für einen Vortrag auch Werben für einen Schirmherren“ (ebd., S. 15).

Bezugnehmend auf die Ebene der lokalen Organisation wendet sich Goffman der Performanz zu. Er unterscheidet verschiedene Produktionsweisen des Vortrags (ebd., S. 18 f.) als unterschiedliche "Quellen der Animation gesprochener Worte" (auswendig gelernter Vortrag, lautes Lesen, freie Rede). Allerdings weist er darauf hin, dass diese Produktionsweisen hinsichtlich des vermittelten Eindrucks nicht frei von Manipulationen seien, gerade in Bezug auf die Lokalität ihrer Organisation: So könne der Anschein allmählicher Verfertigung der gesprochenen Worte beim Sprechen und somit der Eindruck von reflexiver Situativität erweckt werden, obgleich der eigentliche Quell der Animation Auswendiggelerntes sei (siehe auch „conversational style“ bei (Dudley-Evans 1981, 34)). Einen anderen Eindruck zu erwecken, erweist sich aber durchaus als sinnvoll, denn:

Jede [Produktionsweise; R.W.] zeichnet sich durch eine besondere Beziehung zwischen Sprecher und Hörer aus und nimmt dabei eine besondere Haltung gegenüber dem Publikum ein. (Goffman 2005b, ebd.) 
Der Wechsel der Produktionsweise und mit ihm der Wechsel des „Redestatus“ stellen ,zentrale Schaltstellen von Vorträgen“ dar (ebd., S. 19). Hier können Vortragende ihre Haltung gegenüber dem Publikum anpassen und der Interaktionsordnung Rechnung zollen, indem sie ihren Text in die soziale Situation einbetten. In Vorträgen ginge es, entsprechenden Ritualen in direkter Interaktion folgend, vor allem um ,die Verpackung“ (ebd., S. 20). In diesem Sinne fungiert auch der Wechsel des „Redestatus“, den Goffman in Zusammenhang mit seinem Rahmenkonzept (Goffman 1974) stellt, der interaktiven Einbettung:

Ein Wechsel des Redestatus' hat eine Veränderung der Orientierung auf uns selbst wie auch auf die anwesenden Anderen zur Folge und kommt in der Art, wie wir eine Äußerung erzeugen oder rezipieren, zum Ausdruck. Vom Wechsel des Redestatus' zu reden, ähnelt der Rede vom Wechsel unseres Rahmens für Ereignisse. (Goffman 2005b, 42)

Mit der Produktionsweise und dem Redestatus wird daher auch der momentane Rahmen des Sprechereignisses gewechselt. Diese anderen Rahmen entsprechen modulierten Haltungen, die den Vortragenden dazu dienen, den Text ihres Vortrags zu konterkarieren oder vor dem Publikum Distanz zu ihm zu erzeugen. Tatsächlich, so Goffman, sei der reine Informationsgehalt des Textes selbst gar nicht spezifisch für den Vortrag als institutionalisierte Form des Sprechens, denn dieser könne auch gedruckt vermittelt und rezipiert werden. „Modulationen“ des Redestatus (Goffman 2005b, 22) seien daher charakteristisch für Vorträge und kämen in diesen häufiger als in gedruckten Texten vor. Der Redestatuswechsel erlaubt Performer/-innen und Publikum die oben erläuterten Rituale der wechselseitigen Imagepflege sowie die Aufrechterhaltung der Interaktionsordnung zu gewährleisten. Neben der Distanznahme dienen weitere typische Modulationen des Redestatus, die vor allem das betreffen, was Bachtin als Kompositionsstruktur bezeichnet, der Gliederung des Gesagten (z. B. „Textklammern“ und „Texteinschübe“): Derart werden Einleitungen, Höhepunkte und abschließende Bemerkungen nicht allein durch Worte, sondern zudem durch bestimmte Intonationsweisen und stimmliche Modulationen markiert: „Diese rahmenden Phasen werden mit einer Stimme präsentiert, die sich leicht von der im Rest des Vortrags unterscheidet" (ebd., S. 23). Diese Stimmmodulationen zeichneten sich durch einen höheren Persönlichkeitsgrad als das Text-Selbst aus und dienten als Übergänge von diesem fort oder zu diesem zurück (ebd.). Eine besondere Rolle misst Goffman auch „Texteinschüben“ bei, Nebenäußerungen also, „mit denen er [der Redner; R.W.] bewertet, ergänzt und kommentiert, was im Text selbst mitgeteilt wird" (ebd., S. 26): 
Texteinschübe sind von größtem Interesse für die Interaktionsforschung. Auf der einen Seite sind sie am Text orientiert; auf der anderen Seite passen sie sich subtil an die Stimmung des Ereignisses, die besonderen Interessen und die Identität des jeweiligen Publikums an. (ebd.)

So ermöglichen Texteinschübe situativ auf die ,nichtverbal vermittelten Anliegen des Publikums einzugehen“ (ebd., S. 27), dessen Rolle Goffman für die Performanz ausdrücklich hervorhebt: „Ein Publikum, das vom Redner als „teilnahmslos" wahrgenommen wird, [...] bringt den Redner dazu, sich starr an sein Manuskript zu klammern“ (ebd., S. 30). Während umgekehrt „ein Publikum, das „gut" und „entgegenkommend“ sei, ,den Redner dazu verleite[n wird; R.W.], seine Antwort heischenden Äußerungen und Teile auszuweiten“ (ebd.).

Mit den Quellen von „Rauschen“ erläutert Goffman schließlich auch die Bedeutung des Körpers für (die Reparatur von) Störungen effektiver Kommunikation: „Wenn Kommunikation geschieht, gibt es auch Rauschen“ (ebd., S. 33). Dieses könne zum einen ignoriert werden, andererseits könnten „Körperbewegungen“ sowie Einschübe, die das Rauschen thematisieren, zu einer „Verbesserung der Kommunikation führen“ (ebd.). Für Störungen kämen, so Goffman, sowohl akustische als auch visuelle Ursachen während des Vortrags in Betracht. Auch hierbei kommt dem Körper, wie bei der Reparatur von Störungen, eine besondere Rolle zu, denn: „Eine Quelle [des Rauschens; R.W.] schuldet sich der Tatsache, dass Vortragende mit Körpern ausgestattet sind“ (ebd., S. 34). So könnten Nebenhandlungen wie Selbstberührungen, Selbstbeschäftigungen, etc. sowie fehlerhafte Stimmproduktion und „Kodierungsfehler“ (ebd., S. 35 f.), wie falsche Wortwahl, Stottern, etc. die Kommunikation stören.

Gerade hierin, also in der Körperlichkeit und den damit zusammenhängenden Abweichungen von der reinen Informationsvermittlung, sieht Goffman, in Kontrast zum geschriebenen Text, das typische Charakteristikum des Vortrags als Sprechereignis: In den Vortrag fließe das „Rauschen“ mit ein, so Goffman, und stelle dabei sogar „die eigentliche Quelle der Befriedigung der Zuhörer“ dar (ebd., S. 39).

Selbstentblößungen und -offenlegungen kennzeichnen eine Zugänglichkeit, die nur auf die Mitglieder des Präsenzpublikums beschränkt ist - ein sehr viel exklusiverer Anspruch als im Falle eines Lesepublikums (ebd., S. 40).

Goffman überschreitet den Horizont der CA wenigstens in zwei sehr wesentlichen Punkten, die für seine Aufnahme im Kontext der GA bzw. des späteren KoKo relevant sind: Erstens repariert er den stark auf die Strukturelemente des 
Sprechens reduzierten Kommunikationsbegriff der CA, in dem er unter Kommunikation weit mehr fasst als die CA, nicht zuletzt auch aufgrund ihres (zunächst) maßgebenden Erkenntniswerkzeugs, dem Tonband, berücksichtigen konnte. So spielen neben para- vor allem auch nonverbale Gesten, wie an der Spannbreite seiner Gegenstände deutlich wird, für Goffman eine entscheidende, wenn nicht sogar eine größere Rolle als gesprochene Sprache. Zweitens begnügt Goffman sich auch nicht mit der situationalistischen Perspektive der CA, die diese aus der Ethnomethodologie übernommen hat. Zwar ist das konversationsanalytische Sprech-Austausch-System, mit seinen zwei Komponenten und den korrespondierenden drei Regeln, im Sinne seiner Universalität, als übersituativ zu verstehen. Weitere Faktoren, die die Situation überschreiten, sind mit der CA aber kaum $\mathrm{zu}$ erfassen. Hier ist insbesondere der institutionelle Kontext zu nennen, den Goffman, anders als die CA, in seinen Untersuchungen berücksichtigt.

Allerdings ist Goffmans Arbeit zu den Redeweisen (1981), vor dem Hintergrund seiner Nähe zur Soziolinguistik und der CA, anders als die GA, nicht von einem wissenssoziologischen, sondern von einem interaktionistischen Erkenntnisinteresse geprägt. So thematisiert Goffman bei seiner Analyse des Vortrags (lecture) auch an keiner Stelle die spezifische Sphäre der Wissenschaft bzw. die Spezifizität wissenschaftlichen Wissens als thematische Grundlage des Vortrags. Vielmehr fokussiert er ihn als ein Sprechereignis, das zwar einer institutionell-organisierten Vorbereitung bedarf, das aber grundlegend von einer lokal prozessierten normativen Ordnung geprägt ist, die sich in alltäglicher Interaktion herausgebildet hat und von dieser abgeleitet werden muss.

Schließlich sind Goffmans überaus populären, breit rezipierten und zumeist essayistischen Ausführungen, die sich geradezu als ein Gegenprogramm zu den asketisch anmutenden Regelerfassungen der CA lesen lassen (möchten), als konkrete Forschungsanleitungen $\mathrm{m}$. E. generell weniger geeignet. Dies mag auch gar nicht in der Absicht Goffmans gelegen haben, dessen großer Beitrag zur interpretativen Soziologie in gewisser Weise - und in diesem Punkt vergleichbar der Ethnomethodologie - eine Sonderstellung einnimmt. Weder scheint Goffman daran interessiert gewesen zu sein, sich umfassend in den Theorie- oder Methodenkanon der Soziologie einzubringen, noch hat er seine Arbeit in einer Form ausgearbeitet, die es ermöglichen würde, in der empirischen Sozialforschung ohne Weiteres direkt an ihn anzuschließen. Nichtsdestotrotz ist er ein wichtiger Ideengeber für die GA und seine Arbeit als eine wesentliche Hintergrundfolie für die vorliegende Arbeit zu verstehen. ${ }^{15}$

${ }^{15}$ Was hier zuletzt über die Arbeit von Goffman gesagt wurde, gilt ähnlich für den Beitrag von Margaret Mead. Der eigentliche Grund dafür, dass ich ihre Small Conferences (1968) 


\subsection{Die wissenssoziologische GA}

Die wissenssoziologische GA (Luckmann 1986) hingegen zeichnet gerade aus, dass sie ein elaboriertes, umfangreich theoretisch ausgearbeitetes und empirisch erprobtes Forschungsprogramm darstellt. Sie vereint Erkenntnisse aus verschiedenen Forschungskontexten, darunter die Soziolinguistik (Abschnitt 3.1.1), die Luckmannsche Sprachsoziologie (Abschnitt 3.1.2), die CA (Abschnitt 3.1.4) sowie die Arbeiten von Goffman (Abschnitt 3.1.5). Eine Motivation die GA $\mathrm{zu}$ entwickeln, bestand für Luckmann darin, die strukturalistisch informierte Empirie-ferne Abstrahierung, die in den 40er und 50er Jahren des 20. Jahrhunderts in Linguistik und Soziologie gleichermaßen Einzug gehalten hatte (Luckmann 2006, 19), zu überwinden, Linguistik und Soziologie gemeinsam zu denken und so die kommunikativen Formen der gesellschaftlichen Wirklichkeitsproduktion im Sozialkontext zu betrachten. ${ }^{16}$

nicht in dieses Kapitel aufgenommen habe, ist allerdings der, dass sie im Rahmen der GAEntwicklung nicht rezipiert wurden. Dies mag einerseits an dem stark deskriptiv-normativen Charakter dieser thematisch einschlägigen Arbeit liegen, andererseits daran, dass sie keine sozialwissenschaftlich-methodologische Einbettung aufweist. Nichtsdestotrotz stellen M. Meads Ausführungen zu den Small Conferences eine Hintergrundfolie für meine Reflexion des Group-Talks dar. Insbesondere der anhand ihres Ideals von kleinen Konferenzen entwickelte Begriff der Kommunikation unter Wissenschaftler/-innen ist meinem eigenen Begriff der Wissenskommunikation ähnlich: Neben der gegenstandsspezifischen Betonung des Verstehens-Aspekts und des Face-to-Face, besticht er vor allem dadurch, dass M. Mead, neben dem Sprechen und dem gesprochenen Text, auch bereits die Bedeutung anderer Elemente der Kommunikation hervorhebt. Sie spricht von einer ,multi-sensory, many-to-many form of communication“ (M. Mead 1968, S. 7).

Als visuelle Anthropologin erkennt sie die Bedeutung von materiellen Elementen wie Folien oder Tafelaufschriften (ebd., S. 25) für die Analyse der wissenschaftlichen Wissenskommunikation. Im Kontext von Konferenzprotokollen betont sie deshalb schließlich, dass rein textliche Protokolle oder Tonmitschnitte nicht ausreichten, um den Prozess der Wissenskommunikation auf den ,Kleinen Konferenzen“ so zu dokumentieren, dass auch nur den Teilnehmer/-innen selbst, anhand dieser Aufzeichnungstechniken, der Gang der Diskussion bzw. des Erkenntnisgewinns möglich wäre. Sie diskutiert daher, neben der Fotografie, bei der ihr der Ton fehlt, wie bei Tonbandaufzeichnung das Bild (ebd., S. V f.), den Einsatz von Filmkameras ( (ebd., S. 27) und sogar TV-Raum-zu-Raum-Übertragungen (ebd., S. 41).

${ }^{16}$ Kommunikative Gattungen stellen Konstruktionen zweiter Ordnung (Schütz 1971) dar, deren Anwendung selbst keine Gattungstheorie voraussetzt. Vielmehr sind die Regeln, nach denen entsprechende Kommunikationen verlaufen, vergleichbar mit der Interaktionsordnung bei Goffman, Bestandteil des gesellschaftlichen Wissensvorrats. Erst vor diesem Hintergrund können sie ihre Funktion erfüllen, den Kommunizierenden anzuzeigen, wer mit wem in welcher Rolle und unter welchen Umständen kommuniziert etc. und dabei vom Zwang zu spontaner Interpretation entlasten. Die Grundmuster der Kommunikation sind darum nicht 
Kommunikative Gattungen definiert Luckmann vor dem Hintergrund seines wissenssoziologischen Erkenntnisinteresses als „Grundformen der gesellschaftlichen Vermittlung des Wissens“. Sie sind von besonderer sozialer Bedeutung und daher im gesellschaftlichen Wissensvorrat (Berger und Luckmann 1986/1969 [engl. 1966]) abgelagert. So sind sie allgemein zugänglich und dienen dabei als Gesamtmuster, an denen sich das ,institutionalisierte" nicht-spontane Sprechen in Entwurf und Ablauf orientiert. Ziel der GA ist es, diese soziologisch relevanten institutionalisierten Kommunikationsmuster von spontanen kommunikativen Handlungen zu unterscheiden, sie ethnographisch zu beschreiben und zu analysieren.

In „spontanen“ kommunikativen Handlungen baut der Handelnde seine „Botschaft“ Schritt für Schritt zusammen. Er hat eine einigermaßen bewußte kommunikative Absicht, er mag unter besonderen Bedingungen sogar einen kommunikativen Plan entwerfen [...]. Dabei wählt er weitgehend ,selbständig“ aus den ihm in seinem subjektiven Wissensvorrat zur Verfügung stehenden sprachlichen (und allgemeiner: kommunikativen) Mitteln aus. [...] Demgegenüber gibt es wohl in allen Gesellschaften kommunikative Handlungen, in denen sich der Handelnde schon im Entwurf an einem Gesamtmuster orientiert, als dem Mittel, das seinen Zwecken dient. Dieses Gesamtmuster bestimmt weitgehend die Auswahl der verschiedenen Elemente aus dem kommunikativen „Code“, und der Verlauf der Handlung ist hinsichtlich jener Elemente, die vom Gesamtmuster bestimmt sind, verhältnismäßig gut voraussagbar. Wenn solche Gesamtmuster vorliegen, zu Bestandteilen des gesellschaftlichen Wissensvorrats geworden sind und im konkreten kommunikativen Handeln typisch erkennbar sind, wollen wir von kommunikativen Gattungen sprechen. (Luckmann 1986, S. 201 f.)

Wesentlich lassen sich Luckmanns kommunikative Gattungen hinsichtlich ihrer Grundfunktionen beschreiben: Sie dienen als sozial abgeleitete kommunikative Lösungen, die sich für wiederkehrende kommunikative Probleme herausgebildet haben (Luckmann 1986, 203). Mit dem Begriff „Lösung“ (ebd.) nimmt Luckmann Bezug auf den Kulturanthropologen Gehlen, der, vor dem Hintergrund der Conditio Humana, Institutionen im Sinne einer Entlastungsfunktion als Lösungen für Probleme der biologischen Unterbestimmtheit des Menschen definiert (2009[1940]). ${ }^{17}$ Berger und Luckmann (1986/1969[engl. 1966]) schließen

bloße Begriffe zweiter Ordnung, sondern besitzen, als „,reale kulturelle Objekte“, auch eine Wirklichkeit sui generis (Luckmann 1986, S. 203).

${ }^{17}$ Luckmann, der in seiner Sprachsoziologie (1975) den Begriff der institutional language (institutionelle Sprache) gebraucht, macht, in Bezug auf den Begriff der Institution, in der Vorrede zu seinem wissenssoziologischen Gattungskonzept (1986), allerdings einen wesentlichen Unterschied zum späteren KoKo (und der kommunikationssoziologisch aktualisierten GA) deutlich: Wenn er auf die Parallelen zwischen kommunikativen Gattungen und sozialen 
bereits in ihrer Wissenssoziologie an diese Bestimmung an und formulieren im Kontext der Habitualisierung als erster Schritt des Institutionalisierungsprozesses (Abschnitt 2.2.2):

Alles menschliche Tun ist dem Gesetz der Gewöhnung unterworfen. Jede Handlung, die man häufig wiederholt, verfestigt sich zu einem Modell, welches unter Einsparung von Kraft, reproduziert werden kann. (ebd., S. 56)

Auch kommunikative Gattungen weisen, gleichsam als Institutionen der Kommunikation, für Adressierende wie Adressierte eine Entlastungsfunktion auf: Durch sie wird die Summe aller Sprechakte und -weisen vor dem Hintergrund geteilten Wissens und wechselseitiger Reziprozitätsannahmen situativ auf eine Auswahl angemessener Mittel reduziert. Gleichzeitig verfügen sie über eine Anzeigefunktion, die für die Adressat/-innen eine besondere Rolle spielt: Auf Grundlage ihres intersubjektiven Sinns können kommunikative Gattungen intuitiv interpretiert werden, sodass sie spontane Situationsbestimmungen erlauben und der Interaktion dabei unmittelbar Form verleihen. Dies lässt sich anhand des Beispiels der einfachen Gattung (oder Gattungsfamilie) des Grüßens aufzeigen, die es u. a. erlaubt, zufällige Begegnungen spontan zu kommentieren. Dabei muss der Gruß, z. B. ein wohlmeinender Wunsch, nicht allein und nicht einmal vorrangig das ausdrücken, was wir den anderen, denen wir z. B. auf der Straße begegnen, in der Situation eigentlich mitteilen möchten.

Vielmehr gibt die Art des Grußes der Begegnung eine reziprok verständliche und anschlussfähige Form, die, vor dem Hintergrund geteilten Wissens, wechselseitig zu interpretieren erlaubt, wie sich die Begegnung weiterentwickeln wird (Situationsdefinition); z. B. stehenbleiben und mit wechselseitigem Blickkontakt

Institutionen verweist, erklärt er, dass beide, in einem Punkt, kategorisch zu unterscheiden seien: Während nämlich Institutionen Verfestigungen solchen (instrumentellen) Handelns darstellten, das faktisch Veränderungen in der Welt vornehme, würden in kommunikativen Gattungen Lösungen vorliegen, die aus kommunikativem Handeln bestünden. Wenn man diese Gattungen mit Institutionen vergleiche, dürfe man diese daher dennoch nicht gleichsetzen. Gattungen seien eben ,keine Institutionen des Tuns, sondern festgelegte Gesamtmuster des Redens (und allgemeiner: der Kommunikation)“ (Luckmann 1986, S. 203). - Dieses Zitat berührt zwei Konstituenten des KoKo, die diesen von Luckmanns SoKo deutlich unterscheiden lassen: Erstens, dass Luckmann, wie Habermas, instrumentelles und kommunikatives Handeln voneinander trennt. Zweitens die mit der klassischen GA einhergehende Fokussierung auf gesprochene Sprache (Abschnitt 2.2): Während Luckmann kommunikative Gattungen mit einem klaren Bias als „festgelegte Gesamtmuster des Redens“ bezeichnet, werden andere Modi der „Kommunikation“ von ihm nur in Klammern mitbedacht. Dabei erscheint diese Parenthese wie eine nachträgliche Hinzufügung und verdeutlichen m. E., wie stark der Sprachbias bei Luckmann tatsächlich ausgeprägt war. 
aufeinander zugehen oder nach einem kurzen Blickkontakt mit gesenktem Blick weitergehen. Dabei spielen, wie man an dem kleinen Beispiel erkennen kann, neben den gesprochenen Worten auch das soziale Setting, die (paraverbale) Prosodie (d. h. klangliche) und non-verbale Aspekte der Kommunikation (wie z. B. Körperformation und Blickrichtung) eine wichtige Rolle für die ,Art des Grußes“ und damit dafür, der Situation ad hoc und wechselseitig eine Form zu verleihen: Erst auf Grundlage des Zusammenspiels dieser sehr unterschiedlichen Elemente der Kommunikation wird deutlich gemacht, ob man bezweckt, mit der Adressat/in ein (kurzes) Gespräch zu beginnen oder ob der Gruß nur aus Höflichkeit oder gar gepaart mit Unhöflichkeit erfolgte, weil wir keine Lust oder Zeit dazu haben, mit den Gegrüßten zu interagieren etc.

Durch ihre Grundfunktionen (Entlastungs- und Anzeigefunktion) sind kommunikative Gattungen wesentlich für die Stabilität einer gegebenen sozialen Ordnung. Sie stellen erprobtes Rezeptwissen für Kommunikation dar, auf dessen Grundlage Menschen ihre soziale Ordnung in Interaktion situativ (re-) produzieren können. Gattungen zu analysieren, bedeutet daher, den Kodex des kommunikativen Haushalts (Luckmann und Knoblauch 2000, 545) als virtuelles, gesellschaftliches Wissensreservoir fortzuschreiben und dabei Erkenntnisse über Bestand und Wandel einer gegebenen Gesellschaft zu erlangen, die (kommunikativ) handelnd erschaffen, erhalten und weiterentwickelt wird. Die GA ist in diesem Punkt mit der Sequenzanalyse vergleichbar. Während Letztere analytische Einblicke in die mikrosoziologische, lokale Organisation von Interaktionen gewährt, erlaubt Erstere Einblicke in die auf Meso- und Makroebene gelegenen sozialen Relevanzstrukturen, die auch Goffmans Interaktionsordnung umfassen.

\subsubsection{Die Binnenstruktur}

Luckmann (1986) erläutert sein maßgeblich sprachsoziologisches Konzept kommunikativer Gattungen anhand eines zweigliedrigen Grundaufbaus aus Außenund Binnenstruktur. Dabei wendet er sich zunächst der Binnenstruktur seiner kommunikativen Gattungen zu:

[S]ie [die kommunikativen Gattungen; R.W.] haben alle die gleiche „materiale“ Grundlage, nämlich die verschiedenen, in einem gesellschaftlichen Wissensvorrat verfügbaren Zeichensysteme (kommunikative „Codes“) und, zusätzlich in manchen mündlichen Gattungen, die wenigstens teilweise systematisierten, obwohl nicht voll zeichenhaften Ausdrucksformen. Daraus ergeben sich wesentliche Gemeinsamkeiten in der Struktur kommunikativer Gattungen. Die Gemeinsamkeiten, die sich aus der Beziehung zwischen Grundfunktion und „materialer“ Basis ableiten, kann man 
vielleicht am besten als die Binnenstruktur kommunikativer Gattungen bezeichnen. (ebd.)

Die Binnenstruktur kommunikativer Gattungen basiert demnach auf einer spezifischen Auswahl aus der Gesamtheit der im gemeinsamen Wissensvorrat verfügbaren kommunikativen Mittel (Zeichensysteme und ,nicht voll zeichenhafte Ausdrucksformen“). Diese Selektion entspricht dabei der Lösung eines spezifischen Kommunikationsproblems (Entlastungsfunktion). Das bedeutet, dass der Zweck der Kommunikation die Wahl der linguistischen bzw. kommunikativen Mittel aus dem gesellschaftlichen Wissensvorrat weitgehend festlegt. Hierzu zählen

die verschiedensten Ebenen des „Codes“ [...], von der Phonologie, Prosodie zur Semantik und zur Syntax; es kann sich um Grundelemente der „Codes“ und um eingeschliffene Zusammensetzungen von Elementen handeln, und die Vorauswahlen können sich auf sprachliche, ,textuelle“ Aspekte beschränken oder die Verbindung von sprachlichen, gestischen, mimetischen, kinesischen usw. Aspekten festlegen. Die Binnenstruktur einer Gattung besteht somit aus Gesamtmustern recht verschiedenartiger Elemente, die mit verschiedenartiger Verbindlichkeit festgelegt sind: Worte und Phrasen, Gesamtregister, Formeln und formularische Blöcke, rhetorische Figuren und Tropen, Stilmittel wie Metrik, Reimschemata, Listen, Oppositionen usw., Lautmelodien [...], spezifische Regelungen der Dialogizität wie Redezugbestimmungen [...], Reparaturstrategien und Festlegungen von Themen oder jedenfalls Themenbereichen. (Luckmann 1986, 204)

Als Bausteine der Auswahl bzw. des „Gesamtmusters“, das die Binnenstruktur konstituiert, fasst Luckmann u. a. linguistische, literarische und konversationsanalytische Aspekte der Kommunikation. Zudem zählt er auch die typische Verschränkung von Kode-Mustern mit anderen Ausdrucksformen zu den Merkmalen der Binnenstruktur: Er unterscheidet Gattungen die sich neben der Sprache auf deren Verknüpfung mit körperlichen Aspekten des Sprechens beziehen, von anderen, die ausschließlich die Wahl textlicher Elemente festlegen. Außerdem variiere, so Luckmann, die Verbindlichkeit binnenstruktureller Merkmale: Neben den Grundelementen und Mustern, die auf linguistischer Ebene und teilweise in Verschränkung mit körperlichen Aspekten des Sprechens festgelegt würden, erstreckten sich einige Gattungen auch darauf das Thema, das besprochen wird, wenigstens teilweise, zu determinieren.

Zur Charakterisierung der Binnenstruktur einer kommunikativen Gattung sollen sie hier mit einer Gruppe der literarischen Gattungen, dem Drama, verglichen werden. Einige Parallelen aber auch Unterschiede lassen sich dabei verdeutlichen, 
wobei die Bedeutung der Binnenstruktur von kommunikativen Gattungen deutlicher hervortritt: So sind Theaterstücke zwar für die öffentliche Bühnenaufführung geschaffene literarische Werke, die aus der Feder einer Künstler/-in stammen. Ihre textuelle Basis aber ist vergleichbar mit der Binnenstruktur kommunikativer Gattungen: In ihr ist festgelegt, mittels welcher Worte, Sätze und Phrasen (Text) wer zu wem und worüber sprechen soll (kommunikative Rollen). Häufig finden sich zusätzlich zu den zu sprechenden Worten weitere Vorgaben, z. B. mittels welchen Tons, welcher Gestik und Mimik, begleitet von welchen Bewegungen etc., die Worte zu sprechen sind (Handlung). Schließlich finden sich in Dramen auch räumliche Angaben, auf deren Grundlage das Bühnenbild des Theaterstücks festgelegt wird.

Vergleicht man die Binnenstruktur von Dramen mit der von kommunikativen Gattungen, zeigt sich, dass die entsprechende Auswahl, im Alltag genauso wie auf der Theaterbühne, textuelle wie performative Elemente festlegt, auf deren Grundlage die bezweckte (Re-)Produktion einer speziellen kommunikativen Situation ermöglich wird. Dabei ist besonders überraschend, dass sich, wie im Theater auch im Alltag, die gattungsspezifischen Vorgaben bis hinein in die Verschränkung von Sprechen und Performanz erstrecken können: Während Dramaturgie in Dramen naturgemäß eine wesentliche Rolle spielt und räumliche, körperliche und materielle Aspekte der verkörperten Aufführung umfasst, sind vergleichbare Festlegungen tatsächlich auch in kommunikativen Gattungen von Bedeutung: So ist z. B. die Predigt nicht nur mit anderen Worten, sondern auch mit einer anderen Prosodie, Gestik, Mimik und anderen körperlichen Abläufen verbunden als die Präsentation oder der Heiratsantrag. Ob belehrender Ton von der hohen Kanzel, offener Blick auf Augenhöhe oder verträumte Miene auf Knien, die performativen Aspekte sind in kommunikativen Gattungen, neben dem Text, von ebenso großer Charakteristik wie in literarischen Dramen und grundlegend für die Lösung des kommunikativen Problems, auf das sie eine Antwort geben. ${ }^{18}$

Auf wenigstens einen wesentlichen Unterschied macht der Vergleich allerdings auch aufmerksam, der an dieser Stelle als Übergang zu der zweiten Strukturebene des zweigliedrigen Gattungsmodells von Luckmann dienen soll: Während der fiktive Ort eines Bühnenschauspiels in dessen ,Binnenstruktur' festgeschrieben

${ }^{18}$ Der Text eines Dramas stellt das Modell seiner Aufführung bereit, sowie die Binnenstruktur einer kommunikativen Gattung das Modell einer bestimmten Kommunikation bereithält. Dabei würde das literarische Drama, wenn man es als kommunikative (und nicht als literarische) Gattung betrachten wollte, wie ich es hier zum Vergleich tue, allerdings eine Extremform darstellen: Inszenierungen von derartiger Schärfe, wie sie die Wort-für-WortBefolgung der Aufführungen von Klassikern auf der Theaterbühne häufig verlangt, finden sich, in säkularisierten Gesellschaften, vermutlich nur noch beim Militär. 
wird, ist das räumliche Setting der kommunikativen Gattung selbst nicht Bestandteil ihrer Binnenstruktur. Dies trifft allerdings auch auf Dramen zu, sobald man die fiktionale Rahmung gegen den realen Ort ihrer Aufführung eintauscht. Dann nämlich spielen alle Stücke, ob in Dänemark oder am englischen Hof, stets auf Theaterbühnen. Diese organisationale Festlegung wird in der GA allerdings nicht der Binnenstruktur zugeordnet, die die materiale Grundlage der kommunikativen Gattung umfasst, sondern muss auf Ebene dessen verortet werden, was Luckmann als Außenstruktur bezeichnet.

\title{
3.2.2 Die Außenstruktur
}

Mit Außenstruktur bezeichnet Luckmann die institutionellen Rahmenbedingungen, in denen eine spezifische kommunikative Gattung ausgebildet oder etabliert wird. Sie

\begin{abstract}
besteht im Wesentlichen aus vorgefertigten Definitionen kommunikativer Milieus, kommunikativer Situationen und des Typs, der Rolle und der wechselseitigen Beziehung der Handelnden. Diese Definitionen sind natürlich nie vollkommen unabhängig von den vorherrschenden Definitionen gesellschaftlicher Milieus, gesellschaftlicher Situationen und sozialer Akteure - aber sie müssen mit ihnen auch nicht identisch sein. Am nächsten kommen sich die zwei Definitionsarten (in denen üblicherweise Alter, Geschlecht, Status usw. eine Rolle spielen) dann, wenn eine kommunikative Gattung eng mit einer sozialen Institution verbunden ist. (ebd., S. 204).
\end{abstract}

In der Außenstruktur kommunikativer Gattungen liegen also solche Bestimmungen vor, die Gruppen, Situationen, Akteure und ihrer wechselseitigen Beziehungen zueinander (um-)definieren und regeln, wer als wer miteinander in der Gattung kommuniziert (kommunikative und soziale Rollen). Bei diesen außenstrukturellen Vorgaben kann es sich um gattungsspezifische Situations-, Handlungs- und Personaltypen handeln, durch die allgemeine soziale Situationsbzw. Rollenbestimmungen an Bedeutung verlieren. In anderen Fällen, nämlich dann, wenn die kommunikative Gattung eng mit sozialen Institutionen verknüpft ist, behalten die allgemeinen sozialen Typen allerdings ihren determinierenden Charakter und situieren die Kommunikation.

In diesen Fällen sind die Merkmale der Außenstruktur in doppeltem Sinn prägend für die spezifische Kommunikationsweise, die sich anhand einer kommunikativen Gattung beschreiben lässt: Erstens stellen sie den Index dar, der wechselseitig zu verstehen erlaubt, als wer der andere in der gemeinsamen 
Situation auftritt, spricht und handelt (kommunikative Rolle). Andererseits verknüpft die jeweilige Gattungs-Rolle die Situation hier eng mit dem wirklichen institutionellen Kontext der gemeinsamen Interaktion, mit dem Außen einer für alle Teilnehmer/-innen an der Kommunikation verbindlichen sozialen Umwelt, die der gemeinsamen Situation eine verpflichtende Form, eine sozial abgeleitete personelle und thematische Hierarchie verleiht (soziale Rolle). Wenn hinsichtlich der Binnenstruktur, im Vergleich mit den literarischen Gattungen, bereits deutlich wurde, dass Goffman Recht zu geben ist, dass , wir alle Theater spielen', wird dieser Eindruck, durch die Einsicht in die außenstrukturelle Festlegung bestimmter kommunikativer Rollen in kommunikativen Gattungen noch deutlicher. Allerdings dringt mit der Übereinstimmung von allgemeinen und kommunikativen sozialen Typen in ,institutionell-institutionalisierten' Gattungen etwas in die Kommunikation ein, das man als Realitätskern der sozial ausgehärteten gesellschaftlichen Wirklichkeit bezeichnen kann. Dabei besitzen mesound makrostrukturelle Ausgangslagen der Kommunikation in institutionellen Kontexten die maßgebende Prägekraft für die entsprechenden kommunikativen Gattungen.

Während bei vielen (alltäglichen) Gattungen die Bedeutung der sozialen Typen in den Hintergrund tritt (oder absichtlich Kopf steht, wie bei Rollenspielen), ist die Kommunikation in ,institutionell-institutionalisierten ' Gattungen unmittelbar mit der institutionellen Umgebung (Organisationen), in deren Rahmen sie stattfindet, verknüpft. Dies bedeutet, dass die jeweilige kommunikative Rolle der Teilnehmer/-innen in direktem Zusammenhang mit Rollen steht, die die einzelnen in der Organisation auch außerhalb der gattungsförmigen Kommunikation einnehmen. Besonders einleuchtende Beispiele hierfür finden sich abermals in stark normativ reglementierten gesellschaftlichen Subsystemen, wie z. B. der Religion, dem Militär oder auch dem Bildungssystem. Hier werden die kommunikativen Rollen der einzelnen Teilnehmer/-innen an der Kommunikation von sozialen Rollen abgeleitet, die ihre kommunikative Rolle in der Situation transzendieren. So bleibt der Unterschied zwischen Priester/-innen und religiösen Laien nach der Predigt, zwischen vorgesetzten und untergebenen Soldat/-innen jenseits eines konkreten Befehls und zwischen Lehrer/in und Schüler/-in auch außerhalb des Unterrichts bestehen.

Zudem sind die thematischen Fokusse, die in der gemeinsamen Kommunikation zwischen den jeweiligen Gruppen zum Ausdruck gelangen, durch ihre Organisationen stark determiniert, wobei sich der thematischen Bandbreite eine entsprechende Auswahl von in diesen Organisationen typischen Gattungen zuordnen lässt: So stehen Priester und Gläubige im Kontext der katholischen 
Kirche neben der Predigt u. a. vor der regelmäßigen kommunikativen Herausforderung des Seelsorgegesprächs, der Taufe, des Religionsunterrichts, der Kommunion, der Beichte etc. In anderen Religionen ließen sich z. T. dieselben, zum Teil andere Beispiele finden. Für alle diese kommunikativen Probleme wurden im Laufe des sozialen Prozesses innerhalb der Kirche jeweils angemessene kommunikative Lösungen in Form von speziellen kommunikativen institutionellinstitutionalisierten Gattungen entwickelt und etabliert. Ähnlich verhält es sich in anderen Organisationen wie z. B. Schulen oder militärischen Einrichtungen, wo ebenfalls, gemeinsam mit dem Auftreten typischer Situationen, hier zwischen Lehrer/-innen und Schüler/-innen bzw. vorgesetzten und untergebenen Soldat/-innen, kommunikative Gattungen entwickelt wurden, um diese kommunikativen Herausforderungen, gemäß den spezifischen institutionell vorgegebenen Normen zu bewältigen. Hier wird deutlich, dass sich die Relevanzen sozialer Organisationen an deren Kommunikation ablesen lässt. ${ }^{19}$

Binnen- und Außenstruktur bilden bei Luckmann gemeinsam das Gesamtmuster einer kommunikativen Gattung und betten sie damit in ihre Zweckbestimmung und in einen institutionellen Rahmen ein, der Kommunikationssituationen mit unterschiedlichen Verbindlichkeitsgraden umgibt. So können Gattungen in Bezug auf ihre Binnenstruktur und die Auswahl des geeigneten Kodes, aber auch hinsichtlich ihrer institutionellen Vorbestimmtheit mehr oder minder determinierend wirken: Es gibt Situationen, in denen Gattungen zur Anwendung kommen, die wenig von allgemeinen sozialen oder institutionellen Kontexten beeinflusst sind, wie Konversationen, und andere, wie ich an einigen Beispielen verdeutlichen konnte, deren kommunikative Muster stark oder sogar vollständig von ihrer institutionellen Rahmung abhängen, z. B. in Religion, Militär, Bildung oder Wissenschaft. Eine entsprechend große Rolle spielt der institutionelle Rahmen bzw. die Außenstruktur daher auch für Form und Funktion des Group-Talks. Als realzeitliches Face-to-face-Kommunikationsereignis muss er allerdings noch auf einer dritten Strukturebene verortet werden, die in Luckmanns Gattungskonzept selbst noch nicht vorgesehen ist. An dieser Stelle wenden ich mich deshalb empirischen Arbeiten zu, die entweder im Umfeld der Entwicklung von Luckmanns GA entstanden sind oder an sie anschließen.

\footnotetext{
${ }^{19}$ Dieser Zusammenhang, zwischen Außen-, im Sinne sozialer meso- und makrostruktureller Bedingungen der sozialen Situation einerseits und der Außenstruktur kommunikativer Gattungen andererseits, ist vor dem Hintergrund des in meiner Arbeit thematisierten GroupTalks in der beobachteten CNS-Forschungsgruppe, wie sich zeigen wird (Abschnitt 4.1), von besonderer Bedeutung.
} 


\subsubsection{Die tatsächliche bzw. situative Realisierung}

Auf Grundlage des Luckmannschen Gattungsmodells wurde noch in den 1980erJahren eine Reihe von Forschungsprojekten durchgeführt, die sich als empirisches Programm des SoKo verstehen lassen. Diese Gattungsanalysen hatten zum Ziel, entlang des dort beschriebenen gesellschaftlichen Wissensvorrats, den kommunikativen Haushalt (Luckmann 1986, 206) zu erforschen, um so Rückschlüsse auf soziale Relevanzsysteme zu ermöglichen (Bergmann 1987, 42). Einer der ersten empirischen Beiträge zur wissenssoziologischen GA stammt von Luckmanns Mitarbeiter Bergmann (1987). Bergmanns Habilitationsschrift Klatsch. Zur Sozialform der diskreten Indiskretion entstand bereits zwischen 1984 und 1986 im Rahmen seines mit Luckmann durchgeführten DFG-Forschungsprojekts Strukturen und Funktionen von rekonstruktiven Gattungen der alltäglichen Kommunikation. Während die Luckmannsche Sprachsoziologie sowie dessen Gattungskonzept sich im Klatsch nicht systematisch widerspiegeln, kommt Luckmanns Einfluss hier vor allem in den wissenssoziologischen Aspekten der sonst stark konversationsanalytisch geprägten Arbeit zum Ausdruck. So macht Bergmann darauf aufmerksam, dass im Kontext des Klatschs als Sozialform mindestens zwei unterschiedliche Wissensformen unterschieden werden können: Auf der einen Seite das „substantielle Alltagswissen“, ,das sich in unserem Reden über Klatsch manifestiert“ (Bergmann 1987, 27), andererseits das zum Klatschen notwendige ,prozedurale Wissen“ (ebd.), das die Praxis des Klatschens anleitet. Insbesondere das zweite ist für die GA von besonderer Bedeutung.

Der wesentliche Unterschied zwischen den Wissensformen liegt darin, dass das substanzielle Wissen eine theoretisch-rekonstruktive Haltung gegenüber dem kommunikativen Phänomen des Klatschs konstituiert. Als Auslegungswissen, das insbesondere von Effekten der sozialen Erwünschtheit geprägt ist, kann es nicht selbst dazu dienen, Klatsch in der Kommunikation praktisch zu prozessieren. Dafür wird eine andere Wissensform notwendig, die Bergmann als ,prozedurales Wissen“ bezeichnet, das Kommunizierende dazu in die Lage versetzt, die Sozialform situativ zu reproduzieren (Ethnomethoden). Auch wenn, wie Bergmann einräumt, beide Wissensformen nicht trennscharf separiert werden können, dient ihm die Differenzierung dafür, um die Diskrepanz zwischen der diskursiven Ächtung des Phänomens einer- und seiner praktischen Ubiquität anderseits zu erklären (ebd., S. 28). ${ }^{20}$ Hier ist sie deshalb besonders sinnvoll, um zu zeigen,

\footnotetext{
${ }^{20}$ Den Unterschied zwischen den beiden Wissensformen bietet er als Erklärung an, für die Widersprüchlichkeit zwischen dem kommunikativen Handeln einerseits und der theoretischen Einstellung gegenüber der kommunikativen Handlung andererseits: Beides ist von unterschiedlichem Wissen angeleitet. Er weist allerdings auch, wie Bachtin und Luckmann
} 
dass die tatsächliche situative Realisierung von gattungsförmiger Kommunikation einen mit eigenem Wissen ausgestatteten Wirklichkeitsbereich darstellt.

Bergmann weist darauf hin, dass Gattungen auch ein ,gewisses Institutionalisierungsniveau" aufweisen (ebd., S. 40). In diesem Sinne zeichnet sie, vergleichbar mit anderen sozialen Tatsachen (Durkheim 1999[1895]), eine (graduelle) Überindividualität und Transsituativität aus, d. h. sie sind teilweise invariant gegenüber individuellen und situativen Faktoren. Während diese determinierenden Merkmale von kommunikativen Gattungen von Luckmann (1986) explizit betont werden, relativiert Bergmann sie allerdings gegenüber der Situation ihres Auftretens. Damit repräsentiert sein GA-Ansatz einerseits den Übergang von einer maßgeblich theoretischen Konzeption der GA zur Umsetzung eines (radikal-)empirischen Programms, das sich mit der Vollzugswirklichkeit (Garfinkel 1984[1967], 1) gesellschaftlicher Konstruktion befasst. Zum anderen ist diese Verschiebung einer theoretischen Erweiterung der GA geschuldet: Während Gattungen bei Luckmann, basierend auf seiner Sprachsoziologie (Luckmann 1975, 44), selbst in Synthese mit Interaktionismus und Wissenssoziologie strukturalistische Züge tragen, betont Bergmann aus ethnomethodologischer Perspektive das Gegenteil:

Kommunikative Vorgänge werden durch Gattungen nur vorgezeichnet; ihre tatsächliche Realisierung geschieht im Handlungsvollzug und ist damit wie jeder kommunikative Akt den sprachlichen Äußerungsprinzipien (Syntax, Semantik), den interaktiven Organisationsprinzipien (Mechanismus der Redeverteilung, Sequenzformate etc.) und den diversen Kontextualisierungsprinzipien (etwa der Verpflichtung zum rezipientenspezifischen Äußerungszuschnitt) unterworfen. (Bergmann 1987, 40)

In diesem Kontext verweist Bergmann darauf, dass Gattungen nicht mit ihrer Aktualisierung in tatsächlichen kommunikativen Handlungen verwechselt werden dürften. Entscheidend ist für ihn dabei, dass sie, wie er betont, neben einer die Situation transzendierenden Regelhaftigkeit, immer auch lokale Organisationsprinzipien aufwiesen. Diese ,Ethnomethoden“ der Kommunikation sind in der transsituativen Auswahl aus sprachlich-materialen Einzelelementen und Grundmustern (Binnenstruktur) bei Luckmann tatsächlich unterrepräsentiert. In Bergmanns Klatsch-Studie hingegen zeigt sich, dass Klatsch maßgeblich situativ mittels ,Ethnomethoden“ organisiert ist (ebd., S. 56 f.), die dabei, wie

vor ihm, darauf hin, dass die Praxis des Klatschens auch ganz ohne eine Ethnotheorie auskommt. Wie Bachtin und Luckmann betrachtet er Gattungen daher als ,,reale kulturelle Objekte“ (ebd., S. 38). 
Goffmans Interaktionsordnung oder Sacks' Turn-taking-System, nicht dem inhaltlichen Ausdruck, sondern grundlegender der Prozessierung der Kommunikation dienen. Zu diesen ,Techniken", die die lokale Organisation des Sprechereignisses strukturieren, zählt Bergmann in seiner Arbeit z. B. Prä-Sequenzen wie die „Klatscheinladung“ bzw. das „Klatschangebot“.21

Charakteristisch für Bergmanns GA des Klatschs ist so der situationale Charakter seiner Analyse, in dem nicht zuletzt seine ethnomethodologische Ausbildung bei Sacks und Schegloff zum Ausdruck kommt. Dies verdeutlicht er einerseits in einer kurzen methodologischen Vorrede, in der er die Notwendigkeit betont, natürliche Daten zur Grundlage seiner Untersuchung zu machen, die nicht selbst schon rekonstruierenden, sondern registrierenden Charakter besitzen (ebd., S. 49). ${ }^{22}$ Zum anderen drückt er dies auch im Rahmen eines Theoriekapitels aus (ebd., S. 191 ff), das er seiner GA anschließt und wo er bereits mit den Worten einleitet, dass er (mit Goffman) der Auffassung sei, dass Soziologie eine Wirklichkeitswissenschaft sein müsse. In diesem Sinne wolle er nicht den Eindruck erwecken, seine theoretischen Ausführungen seien der Höhepunkt seiner Arbeit (ebd., S. 191). Er möchte, ganz anders vermutlich als Luckmann selbst (vgl. Bergmann \& Luckmann 1999, 7), seine empirische Analyse im Gegenteil ausdrücklich nicht als Vorstudie der Theoriebildung (miss)verstanden wissen.

Auf den wesentlichen Aspekt dieser im soziologischen Kontext als ,radikalempiristisch` zu bezeichnenden Einstellung habe ich bereits hingewiesen: Gleich zu Beginn seiner Ausführungen macht Bergmann darauf aufmerksam, dass Gattungen nicht mit ihrer tatsächlichen Realisierung in konkreten sozialen Situationen verwechselt werden dürften. Diese Feststellung, der ich zustimme, lässt

\footnotetext{
${ }^{21}$ Wie Goffman bereits darlegt, sind direkte Interaktionen stets davon gekennzeichnet, dass wechselseitig Gesichtsverlust droht. Die Interaktionsordnung bzw. korrespondiere Rituale zielen daher darauf, das eigene Selbstbild, sowie das der anderen Teilnehmer/-innen an einer Kommunikation, situativ aufrechtzuerhalten. Dies gilt insbesondere im Kontext einer Gattung wie dem Klatsch, die mit (moralisch-rekonstruktiver) Verachtung belegt ist, wie Bergmann verdeutlicht. Wenn keine Aufforderung zum Klatschen vorliegt, empfiehlt es sich daher, zunächst ein unverbindliches Angebot zu formulieren, bevor man mit dem eigentlichen Klatsch beginnt: „Die Prä-Sequenz besteht in diesem Fall darin, dass der potenzielle Klatschproduzent seinen Kommunikationspartnern zunächst ein Klatschangebot macht und sein Klatschwissen so lange zurückhält, bis von Seiten der potentiellen Klatschrezipienten eine positive Rückmeldung auf dieses Angebot erfolgt ist. Ebenso wie die Klatscheinladung des Rezipienten muss dabei auch das Klatschangebot des Produzenten so präsentiert werden, dass eine negative Reaktion ohne Brüskierung und ein Rückzug ohne Gesichtsverlust möglich sind“ (Bergmann 1987, S. 127).

${ }^{22}$ In diesem Kontext räumt Bergmann allerdings auch ein, dass es ihm - gegenstandsspezifisch - nicht möglich gewesen sei, die für seine Analyse eigentlich idealen ,audio-visuellen“ Daten zu erheben (ebd., S. 55).
} 
sich als klare Kritik an Luckmanns Gattungskonzept verstehen, das einerseits zwar parallel zu Bergmanns Klatsch entstanden ist, andererseits aber eine analytische Ebene, die sich ausdrücklich der lokalen Organisation von Gattungen widmet, vermissen lässt. Entsprechend verwendet Bergmann für diesen Aspekt im Kontext seiner Klatsch-Analyse (unsystematisch) den Begriff der Realisierung, wohingegen er die von Luckmann vorgeschlagenen Begriffe der Binnenund Außenstruktur überhaupt nicht verwendet.

Hier wird m. E. eine Bruchkante sichtbar, die durch die Reibung zwischen dem theoretischen, stark sprachsoziologisch geprägten Gattungskonzept von Luckmann und seiner empirischen Anwendung als gattungsanalytisches Forschungsprogramm, gerade im Kontext der ethnomethodologisch-konversationsanalytisch informierten qualitativen Sozialforschung, aufbricht. Der stark von der Ethnomethodologie geprägte Bergmann hat sich in diesem Spannungsfeld zu einem Ethnomethodologie-typischen (Lynch 1999) weitgehenden Verzicht auf Theoriebegriffe entschieden. Knoblauch hingegen, der ebenfalls Schüler und Mitarbeiter von Luckmann war, inspirierte die Bruchkante dazu, ebenfalls in einer empirischen Arbeit zu kommunikativen Gattungen, eine dritte Strukturebene zu entwickeln, die er Außen- und Binnenstruktur zugesellt: die situative Realisierung (Günthner \& Knoblauch 1994, 708).

Zuvor hatte sich eine Vielzahl der frühen von Luckmann inspirierten Fallstudien zwar mit der gesprochenen Sprache in sozialen Situationen befasst, dabei aber in erster Linie textliche Elemente (die auf der Binnenstruktur der GA liegen) fokussiert. Ihr Erkenntnisinteresse war dabei stark von (sozio-) linguistischen Perspektiven geprägt. Eine Ausnahme stellt dabei vor allem die oben in Grundzügen dargestellte Arbeit von Bergmann dar, der, anders als eine Reihe weiterer prominenter Protagonist/-innen der frühen GA, in der (stark Praxis orientierten) Soziologie zu Hause ist. Die meisten Weggefährt/-innen Luckmanns bei der frühen empirischen Anwendung der GA kommen hingegen aus der Sprachwissenschaft (Susanne Günthner, Helga Kotthoff, Sigrid Baringhorst) und prägten die frühe GA entsprechend von linguistischer Seite, was evtl. dem sprachwissenschaftlichem Bias Luckmanns entspricht. Mit der Einführung einer dritten Analyseebene von kommunikativen Gattungen in die GA zu Anfang der 1990er Jahre (in Günthner \& Knoblauch 1994, 708) manifestiert Knoblauch daher methodologisch zugleich deren ,Empirie-Turn“ zur kommunikationssoziologischen GA.

Der Fokus auf die Situation anstatt auf die präfigurierende Binnenstruktur allein, außenstrukturelle Elemente scheinen nicht zuletzt gegenstandspezifisch bei vielen der frühen GA-Arbeiten ebenfalls eine geringere Rolle gespielt zu haben, verdankt die GA maßgeblich ethnomethodologisch und konversationsanalytisch 
informierten Ansätzen, denen gegenüber Luckmann teilweise eine gewisse Skepsis empfand. Diese Inputs in die GA stammen daher maßgeblich von Bergmann und Knoblauch, die die ,tatsächliche Realisierung“ (Bergmann) bzw. ,situative Realisierung“ (Knoblauch) von kommunikativen Gattungen fokussieren und, wie Knoblauch, dabei das Luckmannsche Konzept systematisch um diese im Rahmen empirischer Sozialforschung entscheidende Dimension bzw. Strukturebene erweitern. Erst mit dieser Erweiterung um die situative Realisierungsebene gerät die kommunikative Gattung weit stärker als zuvor als situatives, interaktionales und lokal organisiertes Ereignis in Betracht, für das auch para- und nonverbale, d. h. performative Aspekte der Kommunikation von Bedeutung sind. Diese methodologische Ergänzung bereitet die GA daher auch auf die stärkere Berücksichtigung von materiellen Objektivationen vor. Dies wird in Arbeiten deutlich, wo im Kontext der GA die Methode der (ursprünglich im ethnomethodologischen Kontext entwickelten) Videoanalyse zur Videographie weiterentwickelt wird (Schnettler und Knoblauch 2007, Schnettler 2001, Tuma, Schnettler und Knoblauch 2013). ${ }^{23}$

Die Erweiterung der GA um die situative Realisierungsebene ist daher von größter Bedeutung für ihre Weiterentwicklung zu dem, was ich mit dem Begriff der kommunikationssoziologischen GA von der Luckmannschen sprachsoziologischen GA abgrenzen möchte. Erst im Rahmen dieser Entwicklung erfährt die GA eine Ausbalancierung zwischen Ethnomethodologie, Linguistik und Sprachsoziologie. Einerseits greift die (Knoblauchsche) kommunikationssoziologische GA die theoretischen Grundlagen auf, die Luckmann aus der Soziolinguistik entwickelt hatte, andererseits verdeutlicht sie, dass im Rahmen der Luckmannschen GA zwischen Binnen- und Außenstruktur die Struktur des eigentlichen Geschehens, die ,Ethnomethoden“ der Interaktion, vernachlässigt worden waren. Zwar darf auch die situative Realisierungsebene nicht mit der Situation selbst verwechselt werden. Jedoch erlaubt sie zu berücksichtigen, wie, in Abgrenzung zu binnenstrukturellen Elementen von kommunikativen Gattungen, auch Merkmale der Situation dazu beitragen, dass kommunikatives Handeln Wirklichkeit erschafft.

Erst in der situativen Realisierung werden die binnenstrukturellen Grundelemente und Muster, vor dem Hintergrund eines spezifischen mehr oder minder

${ }^{23}$ In diesem Kontext muss erwähnt werden, dass die Arbeiten, die seitens linguistischer Forscherinnen, wie Günthner und Kotthoff, zur Entwicklung der GA beigetragen wurden, an dieser Stelle keinesfalls geschmälert werden sollen. Im Gegenteil: Vermutlich aufgrund der ursprünglichen Herkunft der GA aus den Sprach- und Literaturwissenschaften, wurde die GA vor allem in diesen Bereichen stetig ausgebaut, wo ihre Protagonist/-innen bis heute eine Vielzahl von Publikationen liefern und so das von Luckmann avisierte Archiv des „kommunikativen Haushalts“ fortlaufend ausbauen. 
bindenden institutionellen Settings, praktisch zu einer kommunikativen Wirklichkeit verdichtet. Diese realisiert sich in kommunikativem Handeln, das einer spezifischen lokalen Form der Organisation unterworfen ist, wie sie in Sequentialität und Interaktionsordnung zum Ausdruck kommt. Daher vereint erst die kommunikationssoziologische GA die linguistische (Binnenstruktur) und die institutionalistische (Außenstruktur) mit einer ethnomethodologisch informierten Perspektive (situative Realisierung) innerhalb eines gemeinsamen Methodologierahmens, um so die drei maßgeblichen Einflussfaktoren von kommunikativen Gattungen zugleich in den Blick zu bekommen.

Neben [...] rituellen gehören auch konversationelle Merkmale, die die interaktive Organisation kommunikativer Handlungen betreffen und besonders von der Konversationsanalyse aufgezeigt wurden, zur situativen Realisierungsebene. Sie lassen sich durch Muster von Redezugabfolgen und Paarsequenzen (,,adjacency pairs“), wie etwa Fragen und Antworten, Auffordern und Nachkommen der Aufforderung beschreiben. Zur Realisierungsebene zählen auch Strategien der längerfristigen Gesprächsorganisation [...]. Die von der Konversationsanalyse beschriebenen Phänomene - wie Paarsequenzen, Präferenzstrukturen und Strategien der Redezugorganisation - bilden die konversationelle Ebene der situativen Realisierungsebene. Goffman hat darüber hinaus auf weitere Dimensionen der interaktiven Organisation kommunikativer Handlungen [...] aufmerksam gemacht. (Günthner \& Knoblauch 1994, 708 f.)

Hier möchte ich nochmals an den Vergleich kommunikativer Gattungen der sprachsoziologischen GA mit literarischen Dramen erinnern. Mit der Ebene der situativen Realisierung gelangt nun, was bei diesem Vergleich zunächst nicht möglich war, auch die Aufführung selbst zu ihrem Recht als Realität sui generis. Während Binnen- und Außenstruktur, Text und Theaterbühne, die eigentliche Inszenierung gleichsam umstellen, geraten nun auch solche lokalen Regeln in den Blick, die nicht Teil der textuellen, binnenstrukturellen Basis des Stückes sind. Adressiert werden hierbei bestimmte non- und paraverbale Techniken, die Schauspieler/-innen genauso wie Alltagsakteure einsetzen, um ihre gemeinsame Ensembleleistung zu bewältigen (Ethnomethoden). Sie stellen neben der Binnenstruktur ein eigenes völlig unabhängiges Ordnungssystem dar (Interaktionsordnung). Zwar stehen die linguistischen Repertoires bereits in der sprachsoziologischen GA in einem Verhältnis zu anderen Kommunikationsmodi. Dabei bleiben Letztere allerdings weitgehend unreflektiert. Erst auf Ebene der situativen Realisierung hingegen lassen sie sich als vitales kommunikatives Handeln beobachten und beschreiben. In diesem Kontext ist die Entwicklung der Videographie als Methode der kommunikationssoziologischen GA von größter Bedeutung. Während nämlich Tonbänder die Verknüpfung mit 
körperlich-visuellen Aspekten der Kommunikation nur rekonstruktiv in die Analyse mitaufnehmen können, ist die Videoaufzeichnung dazu in der Lage, diese Aspekte ,objektiv' zu registrieren.

Vor dem Hintergrund derart ermöglichter Feinanalysen wird ersichtlich, dass nicht alles, was während der ,Aufführung' einer kommunikativen Gattung geschieht, dem Was der Kommunikation dient - ein Eindruck, der bei der Lukmannschen GA evtl. noch leicht entstehen kann. Vielmehr sind zahlreiche kommunikative Handlungen, wie den Arbeiten der CA und Goffman, aber auch der jüngeren kommunikationssoziologischen Forschungen zu entnehmen ist, dadurch charakterisiert, dass sie auf Ebene der situativen Realisierung dem Wie der Kommunikation geschuldet sind: So können Blicke, Gesten, Mimiken und körperlich-räumliche Aspekte der Kommunikation einerseits zwar durchaus auch dazu dienen, bestimmte Inhalte in Interaktion zu vermitteln. Andererseits sind sie aber mindestens ebenso wichtig dafür, den geregelten Ablauf der Kommunikation überhaupt zu ermöglichen: Sie dienen dazu, die wechselseitigen Rollenerwartungen aufrechtzuerhalten, das Image der an der Kommunikation beteiligten zu wahren, Rederechte zuzubilligen, Wertschätzung und Missfallen auszudrücken, Fehltritte bzw. Abweichungen von dem gattungsspezifisch als angemessen betrachteten Verhalten zu reparieren, thematische Fokusse zu setzen und einzuhalten uvm.

Vor diesem Hintergrund umfasst die situative Realisierungsebene vor allem solches Wissen, das man mit Bergmann als ,prozedural' bezeichnen kann: Dieses prozedurale Wissen (Ethnomethoden) beinhaltet das Knowhow für all die Techniken, die notwendig sind, um in spezifischen Situationen Sinn vermitteln zu können, der dem entspricht, was vermittelt werden soll. Während die Binnenstruktur dieses Was einer gattungsspezifischen Kommunikation umfasst, von der kleinsten Einheit des Wortes bis hin zu größeren Mustern wie Sätzen, Phrasen und rhetorischen Stillmitteln, und die Außenstruktur, mit den auf die Kommunikation einwirkenden allgemeinen sozialen wie institutionellen Situations-, Handlungsund Personaltypen, maßgeblich das Warum einer bestimmten Kommunikation festlegt (und sich dabei systematisch auf das Was auswirkt), finden sich auf der Ebene der situativen Realisierung die Antworten auf die Fragen des Wies der entsprechenden Kommunikation.

\subsection{Weitere Ansätze der GA}

Einen weiteren Strang der Gattungsforschung möchte ich nun noch etwas detaillierter aufnehmen, da er direkt in die Sphäre meiner eigenen Fallstudie führt. 
Meine Arbeit bewegt sich in einem Feld, das durch die sprach- bzw. kommunikationssoziologische GA bislang wenig Aufmerksamkeit erfuhr: die Wissenschaft. Verstehende Soziologie, SoKo und KoKo, mit ihren gemeinsamen Wurzeln in der mundan-phänomenologischen Soziologie von Schütz (Srubar 1988), eint, dass sie sich der Analyse der Alltagswirklichkeit verschrieben haben. Das kommt bei Schütz darin zum Ausdruck, dass er die Fundierung der gemeinsamen Wirklichkeit, wie oben bereits dargestellt, im Alltag verortet. Entsprechend lassen sich Sinnprovinzen als Modulationen des Alltags und der darin entwickelten, tradierten und aktualisierten Wissens-, Erkenntnis- und Kommunikationsformen begreifen.

Daher ist eine Vielzahl der sprach bzw. kommunikationssoziologischen Forschungen (nicht nur in der GA) in Bereichen des Alltags unternommen worden, die kaum oder keine explizite Rahmung im Sinne institutionalisierter Organisation aufweisen. Dies trifft, bedingt, auch auf die eingangs umrissene PowerPointStudie von Knoblauch und Schnettler (2007) zu, die maßgeblich an die CA und die Ausführungen Goffmans zum (wissenschaftlichen) Vortrag bzw. an seine Interaktionsordnung anschließt (Performanz). Auch Goffmans Blick auf den Vortrag als Sprechereignis zeichnet eine starke Alltagsorientierung aus. Er fokussiert nicht die Besonderheit des (wissenschaftlichen) Inhalts, sondern die Allgemeinheit der lokalen Organisation im Sinne einer Ordnung für direkte Interaktion überhaupt. Entsprechend nutzt er den Begriff des Vortrags (lecture) generisch, wodurch er, gattungsanalytisch gesprochen, unterschiedliche Gattungen oder Gattungsvariationen anspricht, die sich in einem sehr breiten Kontinuum darstellen ließen, von der hochschulischen Vorlesung einer Professorin bis hin zur volkshochschulischen Diavortragsreihe eines Landschaftsfotografen.

Auch die CA betont bereits, dass sich sämtliche Sprech-Austausch-Systeme von der lokal organisierten Alltagsform der Konversation ableiten lassen. Entsprechend erläutert Knoblauch (2007), dass es sich bei der Präsentation um eine Gattung handele, die ihre spezifische Form maßgeblich auf Ebene der situativen Realisierung erhalte. In diesem Sinne fokussiert auch er in erster Linie das Wie, d. h. die Strukturen der lokalen Organisation des Präsentierens, die sich in körperlichen Aspekten der Kommunikation manifestieren (Performanz). Die beschriebenen Aspekte der Präsentation sind entsprechend universal und treffen so auch auf den Group-Talk zu. Die Außenstruktur der entsprechenden Situationen allerdings spielt für die Präsentation als Gattung ebenso wie für viele weitere Arbeiten der GA eine eher untergeordnete Rolle, wohingegen der Group-Talk eine starke Außenstruktur aufweist, die seine Form und Funktion weitgehend beeinflusst. Seine konkrete Form steht in engem Zusammenhang mit einer spezifischen institutionellen Umwelt. Vor dem Hintergrund dieses deutlich organisatorisch 
geprägten Settings meiner Fallstudie sind daher Arbeiten aus dem Umfeld der Organisationsforschung von besonderem Interesse, die sich den Gattungen des kommunikativen Handelns in formalen Organisationen widmen und die ich an dieser Stelle daher näher betrachten möchte.

\subsubsection{GA in der Organisationsforschung}

Wenn oben von Organisation die Rede war, dann wurden zumeist lokale mehr oder minder implizite Organisationsprinzipien der Interaktion angesprochen, mittels derer Akteure in sozialen Situationen ihr (kommunikatives) Handeln miteinander koordinieren. Diese lokale, an der Interaktion orientierte Form der Kommunikation, findet stets dann statt, wenn Menschen sich in Kopräsenz wechselseitig wahrnehmen (Goffman). Einer formalen Organisation bedarf es dafür nicht. Bei einer Begegnung auf freiem Feld oder im Wald gelten diese Regeln und die entsprechenden Rituale gleichermaßen. $\mathrm{Zu}$ verwechseln ist diese Form der Organisation aber nicht mit der Organisiertheit innerhalb formaler Organisationen wie Fabriken oder Universitäten. Zwar gilt auch hier Goffmans Interaktionsordnung (Barley 1990, 65), zugleich wirkt aber zusätzlich die formale Organisation auf Grundlage formaler Regeln und institutionellem Wissen auf sämtliche soziale Situationen ein, denen sie (offiziell) als Begegnungsort dient.

Zur Verdeutlichung dieser Tatsache bietet sich ein (einfaches) Modell an, das Organisationen im Sinne von Simmels Differenzierungstheorie (1890) grundlegend als den organizistischen Regeln der Kraftersparnis, Effizienz- und Leistungssteigerung folgende und durch spezielle Regeln ausdifferenzierte (institutionalisierte) Teilbereiche unserer Gesellschaft beschreibt. Im Sinne einer InnenAußen-Differenzierung bildet eine formale Organisation demnach, zum Schutz ihrer zentralen Aufgabenerfüllung, (permeable) System-Umwelt-Grenzen aus (Thompson 1967, 39), die sie durch spezifische Aufnahmekriterien überwacht.

Formale Organisationen bestimmen so, in mehr oder minder detaillierter und determinierender Weise, Regeln, die innerhalb der Organisation gelten sollen und die dabei zugleich die Differenz der Organisation nach außen manifestieren. So wird in einer Fabrik auf Grundlage bestimmter Verfahrenstechniken und professioneller Wissensbestände und durch eine definierte Gruppe angestellter Arbeiter/-innen ein ganz bestimmtes Produkt oder eine bestimmte Produktgruppe hergestellt. In einer Schule sind Lehrer/-innen angestellt, um in Schulgebäuden nach einem festgelegten Lehrplan Schüler/-innen zu unterrichten etc. (Meyer, Scott und Deal 1981). 
Die Ausbildung formaler Organisationsstrukturen kann man sich dabei abermals parallel zu der Entwicklung von sozialen Institutionen bei Berger und Luckmann denken (Abschnitt 2.2.2). Gegebene Organisationen sind dabei häufig bereits Profiteurinnen der Erleichterung von vorgängig institutionalisierten Handlungstypen und Rollen, indem sie bei ihrer Gründung auf diese Muster zurückgreifen können. Diese Übernahme von institutionalisierten Formen erstreckt sich von den Organisationszielen über die Produktionsweise bis zu den Personaltypen, innerhalb derer Angestellte und Arbeiter/-innen das Tagesgeschäft der Organisation erledigen. Wie sich zeigt, werden häufig auch Gattungen, die in Organisationen zur Anwendung kommen, dem gesellschaftlichen Kommunikationshaushalt entnommen.

In den Arbeiten der Organisationswissenschaftlerinnen Wanda Orlikowski und JoAnne Yates kommen in diesem Kontext drei Forschungslinien zusammen, die für die vorliegende Arbeit relevant sind: Erstens betrachten sie explizit formale Organisationen, die auch den Group-Talk rahmen. Zweitens erachten sie Kommunikation als den entscheidenden Prozess innerhalb dieser Organisationen (Orlikowski und Yates 1994, 541). Dabei schließen sie einerseits an den Organisationspsychologen Karl Weick (1985) an, der auf Schütz rekurrierend, organisationale Strukturen als Produkte subjektiver Externalisierungen betrachtet (ebd., S. 220 f.). Zum anderen denken sie diese Grundannahme soziologisch weiter, wobei sie sich Anthony Giddens' Strukturationstheorie (1984) anschließen. Organisationale Strukturen erweisen sich so als Folgen kommunikativen Handelns von mit subjektivem Bewusstsein ausgestatteten Akteuren (Abschnitt 2.1.1), die, aufgrund ihrer Aushärtung, auf das Handeln in Organisationen zurückzuwirken vermögen (Yates und Orlikowski 1992, 299). Last but not least betrachten Yates und Orlikowski organisationale Kommunikationsformen drittens als Strukturen der Organisation. Mit Verweis auf die rhetorische Gattungsanalyse von Carolyn Miller (1984) und Loyd Bitzer (1968) prägen sie daher den Begriff der organisationalen Kommunikationsgattungen (genres of organizational communication; Yates \& Orlikowski 1992, 301):

A genre of organizational communication (e.g., a recommendation letter or a proposal) is a typified communicative action invoked in response to a recurrent situation. The recurrent situation or socially defined need includes the history and nature of established practices, social relations, and communication media within organizations [...]. The resulting genre is characterized by similar substance and form. Substance refers to the social motives, themes, and topics being expressed in the communication [...]. Form refers to the observable physical and linguistic features of the communication $[\ldots]$. There are at least three aspects of form in organizational communication: structural features (e.g., text-formatting devices such as lists and fields and devices 
for structuring group interactions, such as an agenda and a chairperson for a meeting), communication medium (e.g., pen and paper or face to face), and language or symbol system (which would include linguistic characteristics such as formality and the specialized vocabulary of technical or legal jargon). (ebd.)

Genre organisationaler Kommunikation stellen für Yates und Orlikowski typisierte Kommunikationsformen dar, die eine Lösung für wiederkehrende Bedürfnisse der Organisation bereitstellen. Die ,Probleme', die es in Organisationen zu bewältigen gilt, ergeben sich aus den etablierten Praktiken, Beziehungen und Kommunikationsmedien innerhalb der Organisation. Dabei lassen sich Genres nach ihrer Substanz (substance) sowie ihrer Form (form) unterscheiden: Erstere nimmt Bezug auf die Ausdrucksfunktionen der Kommunikation, Letztere auf ihre materiale Basis. Unter der Form subsummieren Yates und Orlikowski allerdings nicht allein die sprachlichen Grundelemente und Muster, sondern darüber hinaus auch Struktureigenschaften der kommunikativen Form sowie deren Mediatisierung. Damit bewegen sie sich in der Nähe der nicht minder stark von der Ethnomethodologie geprägten Science and Technology Studies (STS) (Bijker und Pinch 2012[1987], XXIV), mit denen sie, wie die kommunikationssoziologische GA, nicht nur die Betonung der Materialität bzw. Technik teilen, sondern auch die ethnographische Methodologie.

So fokussieren Yates und Orlikowski Formen der Kommunikation, die über sog. neue Medien mediatisiert sind und in formalen Organisationen, für die sie z. T. ursprünglich entwickelt wurden, traditionell bereits früh eine bedeutende Rolle spielten, z. B. Email (Yates \& Orlikowski 1994), virtuelle Arbeitsumgebungen (2002), das Internet (Kellogg, Orlikowski und Yates 2006) oder PowerPoint (Yates und Orlikowski 2007). Dabei betrachten sie sowohl einzelne Genre gesprochener und geschriebener Sprache, z. B. das Empfehlungsschreiben oder das Meeting (1992), als auch Genrerepertoires (Orlikowski und Yates 1994) als kommunikative Haushalte von Organisationen oder sog. Genresysteme (Orlikowski und Yates 2002). Letztere bezeichnen Strukturen aus zusammenhängenden Gattungen, die in einem bestimmten konsekutiven Verhältnis zueinanderstehen, z. B. die Ausschreibung, das Bewerbungsschreiben, die Einladung zum Bewerbungsgespräch, das Bewerbungsgespräch selbst etc.

In vorliegendem Kontext besonders relevant ist ein Artikel von Kellogg, Yates und Orlikowski (2006), in dem sie das eingangs dieses Abschnitts vorgeschlagene einfache Modell formaler Organisationen, vor dem Hintergrund der oben erläuterten Zeitdiagnose (Abschnitt 2.2.3), wie unsichere Umwelten und verschwimmende Organisation-Umwelt-Grenzen, durch den Begriff der postbürokratischen Organisation konkretisieren. In dieser Arbeit betrachten sie die Kommunikation 
zwischen verschiedenen Communities innerhalb eines Marketingunternehmens (Adweb). Mit Bezug auf das Konzept der „trading zones“ (Galison 1997) fokussieren sie, wie die Wissenskommunikation zwischen den unterschiedlichen Gruppen (Projektmanagement, Design, Technologie sowie Kundenbetreuung) hier organisiert ist:

\begin{abstract}
Working across community boundaries was complicated because the activities and outcomes of one community were interdependent with those of other communities. Furthermore, as conditions on projects changed, new sources of difference and interdependence emerged that had to be addressed. Thus, within-community identities, expertise, and interests were "at stake" for community members because they were often reluctant to compromise on investments they had made to ensure their distinctive competence, status, and position within Adweb and their broader occupational communities beyond the firm. Nevertheless, they had to coordinate across community boundaries to achieve the innovative product demanded by their clients, and to do so in compressed time frames. (ebd., S. 26)
\end{abstract}

Eine besondere Herausforderung für ,postbürokratische Organisationen', wie z. B. die untersuchte Marketingfirma (,Adweb“), stellt die zunehmende Beschleunigung und Diskursivierung ihres Workflows dar. Dieser, so die Autorinnen, sei maßgeblich von der digitalen Arbeitsumgebung, dem Internet, bestimmt, das sich permanent weiterentwickele und dabei neue Kommunikationspotentiale erschließe, deren Nutzung in der Organisation sich schließlich aufdränge (soziale Tatsache). Zudem sei der Gegenstand von Adweb, die Werbung selbst, durch wechselnde Kundenwünsche, Lerneffekte und die Marktkonkurrenz permanenten Entwicklungen unterworfen. Dadurch würden auch die Teams innerhalb der Organisation sich rasch verändern: Neue Mitglieder würden integriert, etablierte in andere Teams wechseln etc.

Vor diesem Hintergrund beobachten die Autorinnen drei Praktiken der grenzüberschreitenden Kommunikationsarbeit: Sichtbarmachung (display practices), Repräsentation (representation practices) und Integration der Arbeitsergebnisse (assembly practices). Zur Sichtbarmachung ihrer Arbeitsfortschritte bedienten sich die Angestellten sowohl des firmeneigenen Intranets (z. B. eines gemeinsamen digitalen Kalenders) als auch der Emailkorrespondenz sowie schließlich eines externen Netzwerks, in das auch die Klienten eingebunden waren. Zur Repräsentation ihrer Arbeit nutzten sie eine große Variation von Gattungen der organisationalen Kommunikation wie Memos, Proposals etc. Von besonderer Bedeutung habe sich aber die Powerpoint-Präsentation erwiesen (ebd., S. 31). Die Integration der einzelnen Arbeitsfortschritte werde schließlich maßgeblich über die digitale Arbeitsumgebung des Intranets erzeugt, auf der interaktiv Kollagen 
aus Präsentationen, Dokumenten und Webseiten erstellt würden, wobei die eigentliche Zusammenfügung der Teilergebnisse, die in den einzelnen Gruppen oder Communities erarbeitet würden, vollzogen werde. Der „Text“, der dabei entstehe, diene den Angestellten anschließend als Repositorium, sodass auf eine große Anzahl vorgefertigter Lösungen für wiederkehrende Probleme zurückgegriffen werden könne.

The availability of documents on the firm's intranet facilitated the assembly of work across time, clients, and functional areas as information was extracted from prior projects (decontextualized) and then included in current project work (recontextualized). As this work was typically represented in a form that had been "road-tested" on earlier projects, it did not require extensive "reprocessing." (ebd., S. 33)

In der Beobachtung stellte sich allerdings auch heraus, dass die für die grenzüberschreitende Koordination zwischen den einzelnen Communities innerhalb der Organisation genutzten Kommunikationsformen unter Inkaufnahme hoher ,Kosten“ praktiziert wurden: So seien zwar einige Gruppen, insbesondere die Technolog/-innen, gerne dazu bereit gewesen, ihre Arbeit sichtbar zu machen und ihren ,Code“ in den Diskurs einzubringen. Andere hingegen, die für das Design zuständigen ,Kreativen' etwa, fühlten sich häufig unwohl dabei, unfertige Arbeiten sichtbar zu machen. Deren Praxis, die sie als individuellen Schöpfungsprozess verstünden, der keine Kooperation erlaube, sei vielmehr davon charakterisiert gewesen, erst fertige Arbeitsresultate vorzustellen. Zudem zeigte sich, dass nicht jede Community gleichermaßen die übliche Form der Präsentation durch PowerPoint schätzte. Sowohl die Technolog/-innen als auch Kreative fühlten sich durch das Medium eingeschränkt: Die Einschätzung, das Medium führe zu Vereinfachung und kreativer Einschränkung, führte in diesen Gruppen zur Ablehnung (ebd., S. 35) von PowerPoint. Alle Communities beklagten außerdem gemeinsam Schwierigkeiten durch die echtzeitliche Sichtbarmachung des Arbeitsfortschritts. Hier war insbesondere die Einbindung der Klient/-innen von Bedeutung. Durch die Kommunikation mit diesen werde ein steter Strom von Kundenfeedback erzeugt, so die Kritik, der das Projekt verändere, worauf die Communities permanent reagieren müssten. Last but not least wüchse der notwendige Aufwand für die Kommunikation auch durch die rege Nutzung des Intranets und die Emailkommunikation, wodurch, wie Yates und Orlikowski betonen, paradoxerweise die grenzübergreifende Kommunikation innerhalb von Organisationen sogar empfindlich gestört werden könne.

Die Autorinnen verdeutlichen, dass der oben als Kommunikativierung erläuterte Prozess an formale Organisationen Anforderungen stellt, die den Aufwand 
der Kommunikationsarbeit erhöhen (Problem). Dabei kommt es zur Etablierung oder Neuausbildung von organisational verbindlichen kommunikativen Mustern, Gattungen, Gattungsrepertoires und -systemen (Lösung). So soll neuen Herausforderungen begegnet werden, wobei gleichzeitig neue Handlungsprobleme geschaffen werden. Die kommunikativen Praktiken der Sichtbarmachung, Repräsentation und Integration stellen typische, gattungsförmige Lösungen für gewachsene Erfordernisse der Kommunikationsarbeit bereit. Gleichzeitig führen die Gattungen der organisationalen Kommunikation aber ihrerseits zu Problemen (wie Kritik etc.), sodass Kommunikation sich auch in Organisationen weit davon entfernt erweist, perfekt zu sein. Vielmehr offenbart sie auch hier eine ihrer Grundeigenschaften: Sie stellt stets die Lösung bis auf Weiteres eines Problems dar, das nur approximativ gelöst werden kann. Das Problem der Kommunikation, das, in der komplex differenzierten, heterarchisch organisierten Lebenswelt sowie in korrespondierenden Sinnprovinzen wie Wirtschaft und Wissenschaft, von wachsender Bedeutung ist.

\subsubsection{Weitere GA-Ansätze im Überblick}

Die vorangegangene Darstellung der GA ist an der Entwicklung zur sprachsoziologischen bzw. kommunikationssoziologischen GA orientiert, an die meine eigene Analyse anschließt. Dabei wurden von mir zahlreiche andere Ansätze auf dem Feld der GA weitgehend oder völlig außer Acht gelassen. Schon im Bereich der hier dargestellten Entwicklung ist meine Arbeit weit davon entfernt, einen vollständigen Forschungsstand abbilden zu wollen. Umso mehr bescheidet sie sich in den Traditionen der rhetorischen (Bitzer 1968, Miller 1984), sprach(Swales 1990) und religionswissenschaftlichen (Gunkel 1901) Gattungsanalyse. Abschließend möchte ich dieses Versäumnis abmildern, indem ich kursorisch auf Publikationen vor allem aus den Bereichen der linguistischen und medienwissenschaftlichen GA hinweise, die sich zur weiterführenden Lektüre bzw. für einen tieferen Einblick in die interdisziplinäre GA empfehlen.

Einen breiten Überblick bietet, u. a. für die Bereiche sprach-, kunst-, musik, theater-, medien-, sozial- und religionswissenschaftliche Gattungsforschung ein von dem Literaturwissenschaftler Rüdiger Zymner (2010) herausgegebener Sammelband. Die Linguistinnen Karin Aijmer und Diana Lewis sind Herausgeber/-innen eines aktuellen Bands im Bereich der Korpuslinguistik mit dem Schwerpunkt eines, neuen“ die Sprechpraxis fokussierenden Ansatzes der vergleichenden Sprachwissenschaft. Diese unterzieht der Linguist Vijay Bhatia (2016) einer Kritik und wendet sie zur kritischen Gattungsanalyse (Critical Genre 
Analysis). 2010 veröffentlichten Piotr Cap und Urszula Okulska (2010) einen linguistischen Sammelband, der sich den Gattungen politischer Kommunikation widmet. Aus soziolinguistischer Perspektive beleuchtet Ahmed Fakhri (2014) Fatwas und Gerichtsurteile als Gattungen arabischer Rechtsauffassungen. Eine aktuelle Monografie zu dem ausgesprochen großen Forschungsfeld der linguistischen Gattungsanalyse im Bereich der Sprache in professionellen und edukativen Kontexten, stellt Sunny Hyon (2018) vor. Neuere Ansätze der medienwissenschaftlichen Gattungsforschung editieren die Medienwissenschaftler Assimakis Tseronis und Charles Forceville in einem Sammelband (2017). Explizit Genres im Film widmet sich Raphälle Moine (2008). Eine Monografie zu TV-Gattungen legt der Film- und Medienwissenschaftler Jason Mittell (2004) vor. Medienwissenschaftlich ist auch die Ausrichtung des Sammelbands von Giuliana Garzone und Cornelia Ilie (2014), der im Kontext der neuen Medien den Wandel etablierter und die Entstehung neuer Gattungen beleuchtet. Ausdrücklich Gattungen des Internets fokussiert der Sammelband von Janet Giltrow und Dieter Stein (2009). Eine medienwissenschaftliche Monografie zum Thema der Gattungsanalyse von Onlineenzyklopädien stellt die Linguistin Anna Tereszkiewicz (2014) vor.

Open Access Dieses Kapitel wird unter der Creative Commons Namensnennung 4.0 International Lizenz (http://creativecommons.org/licenses/by/4.0/deed.de) veröffentlicht, welche die Nutzung, Vervielfältigung, Bearbeitung, Verbreitung und Wiedergabe in jeglichem Medium und Format erlaubt, sofern Sie den/die ursprünglichen Autor(en) und die Quelle ordnungsgemäß nennen, einen Link zur Creative Commons Lizenz beifügen und angeben, ob Änderungen vorgenommen wurden.

Die in diesem Kapitel enthaltenen Bilder und sonstiges Drittmaterial unterliegen ebenfalls der genannten Creative Commons Lizenz, sofern sich aus der Abbildungslegende nichts anderes ergibt. Sofern das betreffende Material nicht unter der genannten Creative Commons Lizenz steht und die betreffende Handlung nicht nach gesetzlichen Vorschriften erlaubt ist, ist für die oben aufgeführten Weiterverwendungen des Materials die Einwilligung des jeweiligen Rechteinhabers einzuholen. 